Check for updates

Cite this: RSC Adv., 2021, 11, 21216

Received 31st March 2021

Accepted 23rd May 2021

DOI: $10.1039 / \mathrm{d} 1 \mathrm{ra0} 2554 \mathrm{f}$

rsc.li/rsc-advances

\section{Socio-economic demands and challenges for non- invasive disease diagnosis through a portable breathalyzer by the incorporation of 2D nanosheets and SMO nanocomposites}

\begin{abstract}
Ramji Kalidoss, (D) *a Radhakrishnan Kothalam, ${ }^{\text {b }}$ A. Manikandan, ${ }^{\text {cd }}$
Saravana Kumar Jaganathan, ${ }^{\text {efg }}$ Anish Khan ${ }^{\text {hi }}$ and Abdullah M. Asiri ${ }^{\text {hi }}$

Breath analysis for non-invasive clinical diagnostics and treatment progression has penetrated the research community owing to the technological developments in novel sensing nanomaterials. The trace level selective detection of volatile organic compounds (VOCs) in breath facilitates the study of physiological disorder and real-time health monitoring. This review focuses on advancements in chemiresistive gas sensor technology for biomarker detection associated with different diseases. Emphasis is placed on selective biomarker detection by semiconducting metal oxide (SMO) nanostructures, 2-dimensional nanomaterials (2DMs) and nanocomposites through various optimization strategies and sensing mechanisms. Their synergistic properties for incorporation in a portable breathalyzer have been elucidated. Furthermore, the socio-economic demands of a breathalyzer in terms of recent establishment of startups globally and challenges of a breathalyzer are critically reviewed. This initiative is aimed at highlighting the challenges and scope for improvement to realize a high performance chemiresistive gas sensor for non-invasive disease diagnosis.
\end{abstract}

\section{Introduction}

Disease diagnosis through exhaled breath analysis has gained momentum during the past decade as the technology offers insights about the subject's internal body metabolism without the need for sample preparation. Among other non-invasive sources (tears, sweat, urine and feces) for disease diagnosis, exhaled breath analysis seems feasible as the ancient Greek physicians had predicted that the aroma of breath provides a certain clue about diagnosis., ${ }^{1,2}$ For instance, the smell of exhaled breath of patients with uncontrolled diabetes is often described as "rotten apple" due to the existence of acetone along with the mixture of inorganic vapors (e.g., $\mathrm{NO}, \mathrm{CO}_{2}$ etc.), volatile organic compounds (e.g., acetone, methyl nitrate, isoprene etc.) and other non-volatile vapors (e.g., nitrogen, cytokines etc.). ${ }^{3}$

The advent of modern breath analysis came into existence when Pauling and his team in 1971 discovered more than 200
VOCs in human breath due to the biochemical pathways resulting through the physiological process. ${ }^{4}$ Usually, this mixture of vapors along with approximately 3500 chemical species existing in human exhaled breath have been identified by various analytical techniques including gas chromatographymass spectrometry (GC-MS), flame ionization spectrometry (FIS) and photo ionization detection (PID). ${ }^{5-11}$ However, these methods are inadequate for routine breath biomarker monitoring as they rely on sophisticated laboratory equipment, trained technicians, and time consuming and complex sample preparation procedures leading to the lack of real time quantitative data. Thereby limiting the portability and so eliminates the possibility of point of care real time diagnosis. Hence the global scientific community had focused their efforts on developing a portable instrumentation for the real-time quantification of biomarkers for the disease diagnosis through exhaled breath.

\footnotetext{
${ }^{a}$ Department of Biomedical Engineering, Bharath Institute of Higher Education and Research, Selaiyur, Tamil Nadu, 600 073, India. E-mail: ramji.sat@gmail.com; Tel: +91-9840-959832

${ }^{b}$ Department of Chemistry, College of Engineering and Technology, SRM Institute of Science and Technology, Kattankulathur, Tamil Nadu 603 203, India

${ }^{c}$ Department of Chemistry, Bharath Institute of Higher Education and Research, Selaiyur, Tamil Nadu, 600 073, India

${ }^{d}$ Centre for Nanoscience and Nanotechnology, Bharath Institute of Higher Education and Research, Selaiyur, Tamil Nadu, 600 073, India
}

${ }^{e}$ Bionanotechnology Research Group, Ton Duc Thang University, Ho Chi Minh City, Vietnam

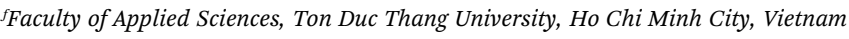
${ }^{g}$ Department of Engineering, Faculty of Science and Engineering, University of Hull, HU6 7RX, UK. E-mail: saravana@tdtu.edu.vn

${ }^{h}$ Chemistry Department, Faculty of Science, King Abdulaziz University, Jeddah 21589, Saudi Arabia

${ }^{i}$ Center of Excellence for Advanced Materials Research, King Abdulaziz University, Jeddah 21589, Saudi Arabia 
Table 1 List of breath biomarkers and their corresponding diseases

\begin{tabular}{lll}
\hline Biomarker & Disease & Ref. \\
\hline $\begin{array}{l}\text { Ethyl butanoate } \\
\text { Ammonia }\end{array}$ & $\begin{array}{l}\text { COVID-19 } \\
\text { Chronic kidney disease, liver } \\
\text { dysfunction }\end{array}$ & 16 \\
$\mathrm{H}_{2} \mathrm{~S}$ & Halitosis & 17 and 18 \\
$\mathrm{NO}$ & Asthma & 19 and 20 \\
$\mathrm{HCHO}$, toluene, & Lung cancer & 21 and 22 \\
benzene & & 23 and 24 \\
Acetone & Type 1 diabetes & \\
& Type 2 diabetes & 25 and 26 \\
$\mathrm{CH}_{4}$ & Intestinal anaerobes & 27 and 28 \\
Ethanol & Alcohol consumption & 29 and 30 \\
\hline
\end{tabular}

The composition of VOCs range between parts per million (ppm) to parts per billion (ppb) that varies quantitatively and qualitatively for every individual similar to unique fingerprints. ${ }^{\mathbf{1 2}}$ These VOCs may originate from cellular levels due to their fundamental body processes ${ }^{\mathbf{1 3}}$ and metabolisms in blood ${ }^{\mathbf{1 4}}$ that plays a vital role in altering the concentration of VOCs. Other sources include inhaled atmospheric air, airway surfaces and tissues throughout the body. As the blood collects all the compounds during bodily metabolism and interacts with lung, they appear in breath. ${ }^{15} 54$ VOCs at elevated concentration indicates several health risks related to gastrointestinal, respiratory systems and metabolic disorders such as halitosis, renal failure, diabetes, chronic liver and kidney diseases few of them listed in Table $1 .^{31,32}$ An increased concentration of ammonia is closely associated with renal disease, acetone with diabetes mellitus (DM) and nitric oxide with chronic obstructive pulmonary disease (COPD). ${ }^{33}$ Since all this VOC appear in the breath because of certain body metabolisms, these endogenous gases resolve practical information on the possible disease and hence it is the perfect indication of any disease. Accurate quantification of these biomarkers provides the feasibility of non-invasive disease detection through exhaled breath.

The availability of unlimited sample quantity even during unconsciousness may become vital in emergency situations, for continuous monitoring of disease progression and the effect of medication in short time period..$^{34,35}$ Whereas, other noninvasive sources such as saliva, sweat, urine and feces need human intervention limiting the diagnostic capabilities at the situation of emergencies. While the biomarkers from each source originate from the fundamental body metabolism, exhaled breath is reliable as it eliminates the social awkwardness or an embarrassment to the patients during sample collection. Apart from social consideration, other non-invasive sources possess certain issues in terms of stability of the sample. ${ }^{36}$ Moreover with the capability of repeated and self sampling, breath analysis are considered to be truly noninvasive and can be performed easily without any embarrassment or discomfort. ${ }^{37}$ Also, it does not present burden to the subject being tested and the ease of sampling offers the advantage of delivering result on spot instead of the traditional laboratory sample preparation and analysis. ${ }^{38}$ Hence, the significance of breath analysis lies on eliminating the pre- analytical and post-analytical procedure along with the mailing of test reports to the concerned subject. Furthermore, as the biomarkers in breath appear due to the fundamental body metabolism at cellular level, diseases may be identified at early stage which is the need of the decade for different cancers that could be cured, if identified at preliminary stage. ${ }^{39,40}$ Breath analysis may permit bedside and personalized home care monitoring, thus could be inexpensive and allows frequent testing for proper control of the disease progression and the effect of medications. ${ }^{41}$ Thus offers an inexpensive replacement for the traditional laboratory analytical tests.

However, there are numerous challenges to be addressed to bring a portable breathalyzer to the commercial market. The high complexity of breath samples leads to misinterpretation of results. ${ }^{42}$ The exhaled biomarkers not only emanate from fundamental body processes but also from the exogenous production by different sources. Breath sampling procedure is not yet standardized leading to the unawareness of sample collection from either nasal or oral cavity. Even though, after the collection of idealized sample, extrinsic factors such as temperature and humidity may influence the outcome of the diagnosis. Furthermore, the level of data interpretation needs standardization to develop a cloud of breathprint database from laboratories across the globe representing a reference standard for clinical practices. ${ }^{43}$

Although, limited number of breathalyzer were recognized by international guidelines and used in patients. Among them ethanol breath test, nitric oxide breath test to diagnose asthma, urea breath test for the diagnosis of Helicobacter pylori and hydrogen breathalyzer for small intestine bacterial overgrowth are currently in research practices. ${ }^{\mathbf{4 4 - 4 8}}$ Nevertheless, there is no single breath test act as stand-alone diagnostic test and only act as a pre-screening tool.

Incorporation of nanomaterials in gas sensors has attracted research interests owing to their unique physic-chemical properties. Gas sensor technologies are classified based on their differences in working principle and device structures. Broadly it is categorized into technologies that rely on the change in electrical and other properties including optical, calorimetric and acoustic properties. The reliability of technologies based on variations in electrical properties such as field effect transistors (FET), surface work function transistors (SWF) and chemiresistors are suitable for exact quantification of breath biomarkers in the range of parts per billion to parts per million. Among them, chemiresistors are widely explored due to their ease in fabrication and miniaturization, simplicity in operation and demands low power. ${ }^{49}$

Hence, the international breath research community is focusing on nanostructured chemi-resistive gas sensors for sensitive and selective detection of breath biomarkers. Herein, we will review SMO and 2DM nanocomposites in chemiresistive gas sensing device configuration for the development of breathalyzers. Their corresponding sensing mechanisms and performance to various biomarkers was highlighted along with the social demands, challenges and regulatory aspects in the hope of directing future research towards non-invasive disease diagnosis through portable breathalyzers. 


\section{Chemi-resistors}

Chemiresistors consists of a sensing film supported on an inert substrate where interdigitated or two metallic electrodes on their either side are deposited and a heater printed at the backside. ${ }^{50}$ This gas sensor device configuration was explored in sensing various biomarkers including acetone, nitrous oxide, ammonia etc. and put to use for clinical trials..$^{51-53}$ Fig. 1 depicts a schematic of chemiresistor, fabricated by spin coating the graphene nanocomposite sensing film on alumina substrate with electrodes and heater printed on the either side. The sensor was explored for acetone sensing properties in presence of other interfering biomarkers along with humidity in exhaled breath and used in clinical trials. ${ }^{54}$ The change in electrical properties of the sensors depends on the concentration of target biomarker. Various SMOs of different nanostructures have received a steady growth for their low cost fabrication process, reliable measuring electronics that demand very low power consumption. ${ }^{55,56}$ Indeed, the non-invasive sensing devices for clinical applications must possess satisfactory portability and affordable cost in addition to their demonstrated sensor performances. Hence it has spurred the interest of the international breath research community to develop an economical hand-held chemi-sensor that is capable of monitoring biomarkers in exhaled breath. The nanomaterials based chemiresistive sensors' parameters such as sensitivity, selectivity, repeatability, response and recovery time can be optimized by altering the characteristics of the sensing material and their definition were given as follows:

Relative response: ratio of resistance of the sensor in the ambient atmosphere to the resistance to the exposure of acetone of varying concentration. ${ }^{57}$

$$
S=\left(R_{\mathrm{a}} / R_{\mathrm{g}}\right)-1
$$

Sensitivity: change in relative response with respect to the change in gas concentration. ${ }^{57}$

Selectivity: measure of the relative response of other interfering biomarkers with respect to acetone.

Repeatability: measure of variation in relative response for the same gas concentration under the same experimental conditions.

Stability: measure of depreciation in sensor performance over a period of 1 month.

Response and recovery time: time taken by the sensor to reach $90 \%$ resistance change of the final equilibrium value. ${ }^{58}$

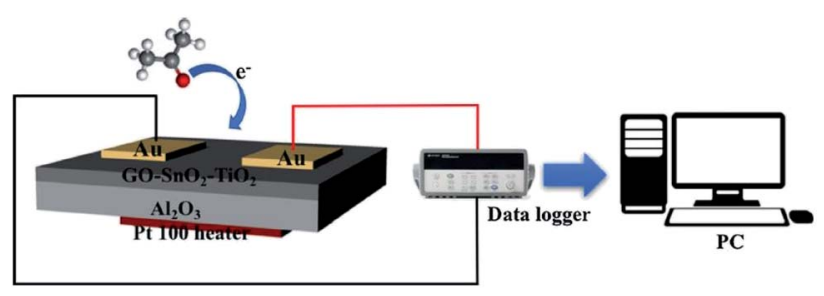

Fig. 1 Schematic illustration of chemiresistor gas sensing device configuration reproduced from ref. 54 with permission from Elsevier, Copyright 2021
The basic sensing mechanism of these SMOs depends on the change in carrier concentration of the sensing material during gas interaction. This interaction may result in an increase or decrease in electrical resistance or conductivity. ${ }^{59}$ n-type SMOs resistance decreases for reducing gas and increase for oxidizing gas from the baseline resistance. Meanwhile, a vice versa phenomenon occurs for p-type SMOs, where resistance decrease for oxidizing gases and increase for reducing gases. ${ }^{59}$ Commonly, chemiresistors exhibit a change in its electrical resistance in the presence of specific target analyte it is engineered to, based on the following mechanisms.

\subsection{Surface adsorbed oxygen ion mechanism}

Conventional SMO gas sensors exhibit a change in its electrical resistance by the redox reaction between the atmospheric oxygen ions and target analyte adsorbed on the surface of the sensing film. In an operating temperature between $200-500{ }^{\circ} \mathrm{C}$, the atmospheric oxygen are ionized to $\mathrm{O}^{-}, \mathrm{O}^{2-}$ and $\mathrm{O}_{2}{ }^{-}$by gaining electrons from the conduction band of the sensing film leading to oxidation, causing changes in its electrical resistance termed as baseline (Fig. 2a). The vicinity of oxidizing/reducing target vapor near the sensing film reacts with the ionized oxygen causing increase/decrease in its electrical resistance. ${ }^{60}$ For example, reducing carbon monoxide biomarker decreases the resistance from baseline (Fig. 2b) by contributing electrons as depicted in the equation,

$$
\mathrm{CO}_{(\text {gas })}+\mathrm{O}_{(\text {ads })}^{-}=\mathrm{CO}_{2 \text { (gas) }}+\mathrm{e}^{-}
$$

In the presence of oxidizing $\mathrm{NO}_{2}$ biomarker, the resistance increases from the baseline as it gains electrons from the sensing film as depicted in the equation,

$$
\mathrm{NO}_{2}+\mathrm{e}^{-}=\mathrm{NO}^{2-}
$$

The basic challenge in such mechanism involves operating at higher temperature for physisorption and chemisorption of atmospheric oxygen. Also, the ionized oxygen species depends on the operating temperature, an important criteria for stabilizing the baseline. The molecular species of oxygen are high compared to atomic species at temperatures less than $150{ }^{\circ} \mathrm{C} .{ }^{61}$ However, gas interaction occurs throughout the surface of the sensing material favorable for the transduction of whole concentration of target analyte at the vicinity of sensing material. ${ }^{62,63}$

\subsection{Charge transfer mechanism}

The gas sensing mechanism of $2 \mathrm{D}$ layered nanomaterial such as graphene, $\mathrm{MoS}_{2}$ etc. differs from conventional SMO sensors by charge transfer process. The electrical resistance changes due to the adsorption, charge transfer and desorption of target analyte on the sensing film. The material acts as either donor or acceptor, depending on the nature of the target analyte, leading to a different transfer direction and quantities of charges. Once reexposed to air, desorption of target analyte leads the resistance to its baseline. ${ }^{64}$ Fig. 3 shows the charge transfer and density 
(a)

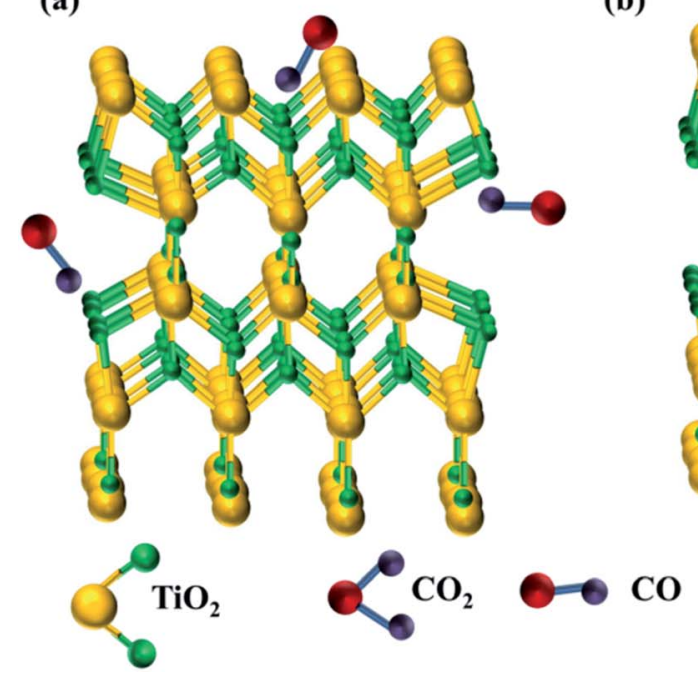

(b)

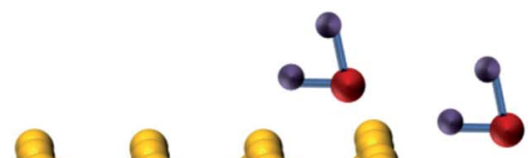

Fig. 2 (a) lonized oxygen ions adsorbed on the surface of the sensing film and (b) CO vapor interacts with ionized oxygen ions giving back electrons to SMOs.

difference between n-type monolayer $\mathrm{MoS}_{2}$ with a donor $\left(\mathrm{NH}_{3}\right)$ and acceptor (CO), where green region represents charge accumulation and red region shows charge depletion regions. The free electrons in the donor vapor $\left(\mathrm{NH}_{3}\right)$ donates electron onto the $\mathrm{MoS}_{2}$ monolayer leading to an increase in charge carrier thus decrease in resistance. On the contrary, charge transfer from the conduction band of the n-type $\mathrm{MoS}_{2}$ to the acceptor vapor (CO) causes the charge density to decrease and increase in electrical resistance of n-type $\mathrm{MoS}_{2} \cdot{ }^{65}$ Unlike, the oxygen ion mechanism, physisorption dominates the adsorption of target analyte in two dimensional nanomaterials. ${ }^{66}$ Physisorption being a weak force and un-directional, strong and selective binding of analyte is hindered and lead to sluggish recovery, respectively.

\subsection{Band bending mechanism}

Hybridization of SMOs with 2DMs creates heterojunction at the interface due the difference in their work function. Hence an obvious difference in Fermi energy levels causes an energy barrier height $(\Delta E)$ leading to accumulation and depletion region at the interface. The vicinity of target analyte near the heterojunction leads to the equalization of Fermi level due to band bending. Fig. 4 shows the energy band structure diagram
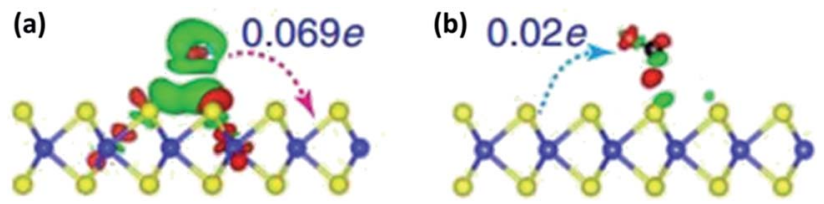

Fig. 3 Difference in charge density and transfer process of (a) $\mathrm{NH}_{3}$ and (b) $\mathrm{CO}$ on monolayer $\mathrm{MoS}_{2}$ reproduced from ref. 65 with permission from Springer, Copyright 2021. The blue and yellow balls represent Mo and $\mathrm{S}$ atoms. The red and green charge distribution corresponds to charge accumulation and depletion. of $\mathrm{RGO} / \mathrm{SnO}_{2}$ before and after vapor infusion. Hybridization of $\mathrm{SnO}_{2}$ and RGO with a work function of $4.5 \mathrm{eV}$ and $5.32 \mathrm{eV}$ respectively causes a difference in Fermi energy levels (Fig. 6a). Further, infusion of donor vapor (acetone) leads to transfer of charge from lower work function $\left(\mathrm{SnO}_{2}\right)$ to higher work function (RGO) tending to equalize the Fermi energy levels (Fig. 6b). This change in interfacial barrier causes a change in current flow characteristics across the rectifying heterojunction. ${ }^{67}$ The hybridization elucidates peculiar properties due to the synergistic effect between SMO and 2DMs. The band bending favors electron accumulation and chemisorption of donor species. The variation in band bending generates a more pronounced resistance variation which improves the gas sensing performance. $^{68}$

Important milestones had been achieved in the way of noninvasive diseases diagnosis through portable breath analyzers by the discussed sensing mechanisms. Peng et al. ${ }^{69}$ had developed a device based on an array of chemiresistive nine functionalized gold nanoparticles to distinguish between healthy and lung cancer patients' breath. Recently, Blaikie et al. ${ }^{70}$ had demonstrated a compact device for the estimation of acetone concentrations under fasting, exercise and normal conditions based on cavity enhanced spectroscopic technique. Sun et al. ${ }^{71}$ had developed a transportable device to distinguish type-2 diabetic subjects from healthy subjects and validated with GCMS with 600 breath samples. Gouma and team had demonstrated portable breath analyzers based on chemiresistive principle for various diseases (diabetes, renal diseases, lung diseases). ${ }^{72-78}$

With the advancements of data acquisition instruments, the response to breath input from gas sensors can be digitized and transmitted to a computer for further signal preprocessing and feature extraction. Furthermore recent development of machine learning techniques provides better classification accuracy 
(a)

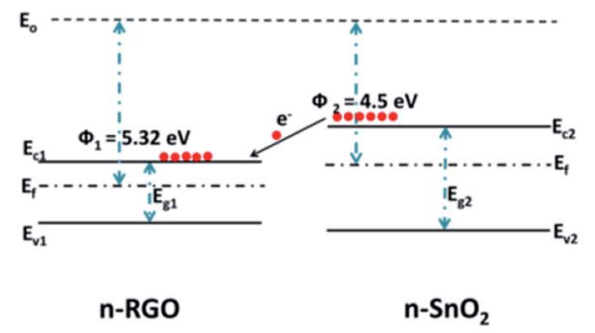

(b)

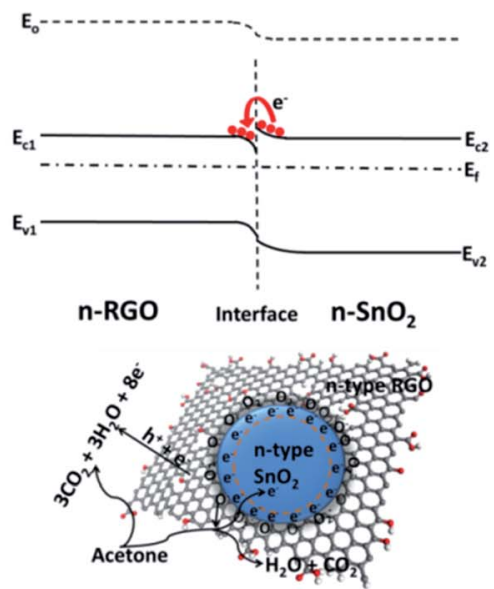

Fig. 4 Energy band diagram of $\mathrm{RGO} / \mathrm{SnO}_{2}$ (a) before and (b) after gas infusion reproduced from ref. 67 with permission from American Chemical Society, Copyright 2021

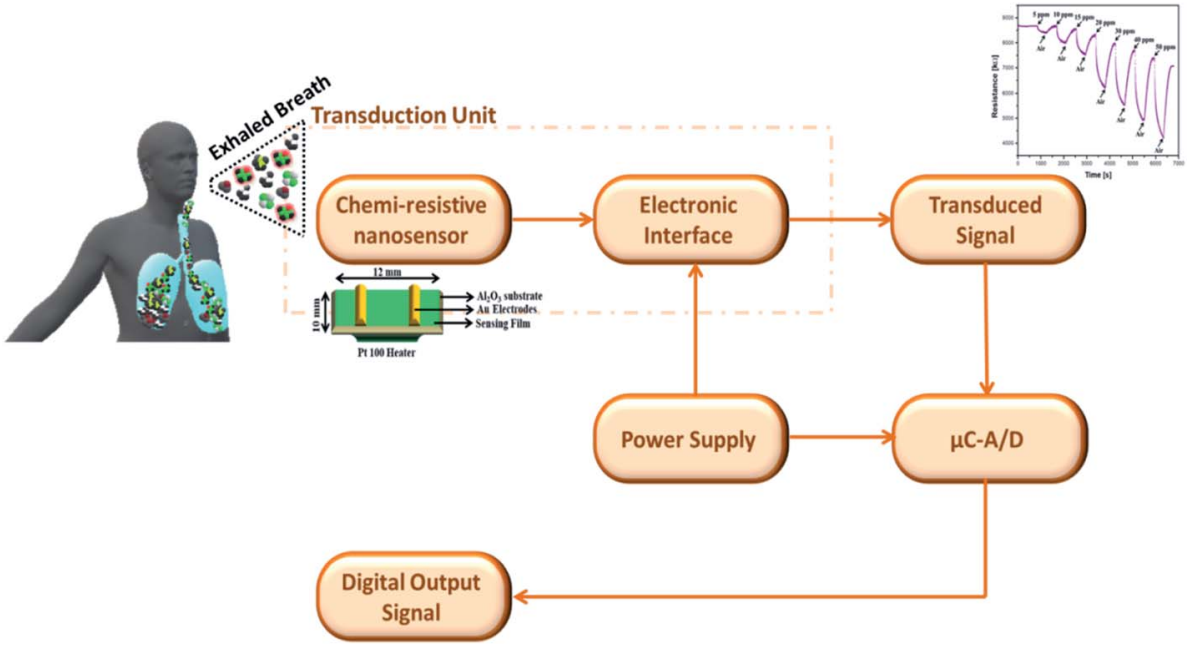

Fig. 5 Block diagrammatic representation of chemi-resistive nanosensors in breath analysis application.

between healthy and diseased subjects. Hence, there is scope for improvement in each block represented in Fig. 5 .

\section{Nanomaterials as chemi-resistive gas sensors for breath analysis}

VOCs exhaled from human breath provide information about the fundamental cellular mechanism which when detected quantitatively and qualitatively favors early detection of disease limiting further complications. This way of disease diagnosis had its footprint from the ancient times associating fruity like breath odor with diabetes mellitus, fishy with liver complications and urine like breath odor with renal failure. After the advent of modern equipment, approximately 30 VOCs with elevated concentrations in breath have been associated with halitosis, diabetes mellitus, kidney malfunction, asthma and different cancers. Over the past decades considerable efforts have been focused on nanostructured materials for the detection of various VOCs with better sensing performances. Materials at nanoscale possess peculiar property compared to their bulk counterpart. Exploiting these properties by controlling their size and shape in the form of nanorods, nanowires, nanosphere improved the gas sensing performance. Moreover, their working conditions including the operating temperature were found to significantly improve the detection capabilities selective to breath biomarkers. ${ }^{79}$ The motivation in the following section is to discuss these optimization strategies of promising nanomaterials as potential gas sensors incorporated in a breathalyzer for the detection of various disease biomarkers in exhaled breath. 


\subsection{Semiconducting metal oxide (SMO) nanostructures}

Several different categories of material exhibit chemiresistive property. Among them, SMOs dominate as a superior gas sensing materials due to their capability to sense a wide variety of gases (oxidizing and reducing gases) and availability of numerous material choices. ${ }^{\mathbf{8 0}}$ Moreover, as they are simple in operation and demands low power, SMOs were largely applied in gas and solvent leak detectors in semiconductor industries, environmental monitoring, food processing, agricultural industry and medical diagnosis. ${ }^{81}$ The first commercial SMO sensor at the beginning of 1970 s used amorphous $\mathrm{SnO}_{2}$. Sensors made of $\mathrm{SnO}_{2}$ nanoparticles possess numerous advantages that include higher sensitivity, ability to operate at lower working temperature and thermally stable structure. This gas sensor was fabricated and patented by Taguchi which was later commercialized by Figaro Inc. The sensor was used for gas leak alarms in factories and residences to prevent fire accidents. $^{82}$ The demand for high performance gas sensors for various applications with low power consumption had diverted the research efforts towards SMOs as gas sensors. Moreover, these SMOs can be altered to deliver high sensing performance by varying the concentration of dopant incorporated, controllable morphology, methodology of sensing material preparation and tailoring physical/chemical properties. ${ }^{\mathbf{8 3 - 8 6}}$ However, sensitivity and selectivity being a primary sensing performance, various above mentioned optimization trials have been best possibly utilized.

The intriguing property of SMOs that it appears in diverse shapes (nano spear, nanowires, nanobelts and nanotubes) favors more interaction sites for target biomarkers. Thus, leading to better sensing performances by optimizing their morphology and tailoring its physico-chemical properties. The permeable and porous structures of metal oxide are explored beneficial for the efficient gas diffusion and entire electron depletion accordingly. The high sensing performances of metal oxides are defined by low detection limits and short recovery times. ${ }^{87,88}$ Numerous SMO nanostructures such as $\mathrm{SnO}_{2}, \mathrm{WO}_{3}$, $\mathrm{In}_{2} \mathrm{O}_{3}, \mathrm{NiO}, \mathrm{ZnO}, \mathrm{CuO}, \mathrm{Co}_{3} \mathrm{O}_{4}$ has been utilized as standalone materials for the detection of various biomarkers. ${ }^{89}$ Jiang et al., optimized 3 variations of the preparation procedure to synthesize $\mathrm{SnO}_{2}$ hollow nanotube observed from the TEM image shown in Fig. 6a. The detection capabilities of the prepared 1dimensional hollow nanotube $\mathrm{SnO}_{2}$ were explored towards asthma biomarker $\left(\mathrm{NO}_{x}\right)$. The sensors were capable of sensing $\mathrm{NO}_{x}$ at room temperature in the concentration ranging between 9.7 ppb to 97 ppm well below breath $\mathrm{NO}_{x}$ concentration with a faster response time of $20 \mathrm{~s}$ for $9.7 \mathrm{ppb}$ and $6 \mathrm{~s}$ for $9.7 \mathrm{ppm}$ (Fig. 6b). These sensing performances of the $\mathrm{SnO}_{2}$ nanostructured chemi-resistive sensors were attributed to its novel morphology favorable for gas interaction sites and the exposure of dominant crystal facets (101). ${ }^{90}$ The dependence of sensing performance on the morphology was further established by $\mathrm{Xu}$

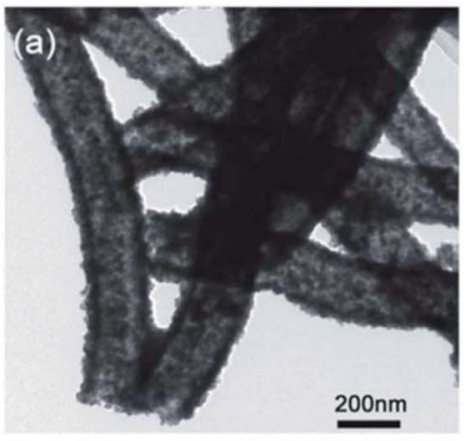

(d)

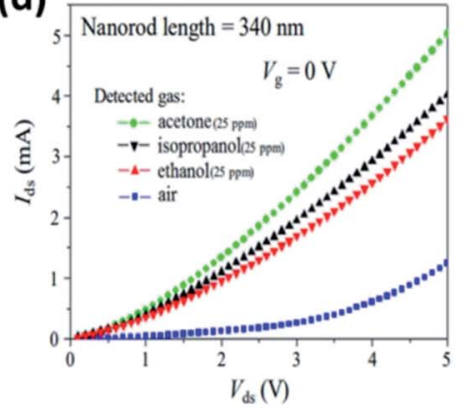

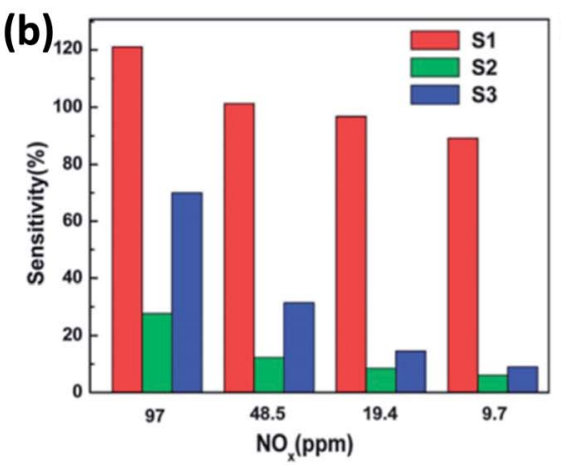

(e)

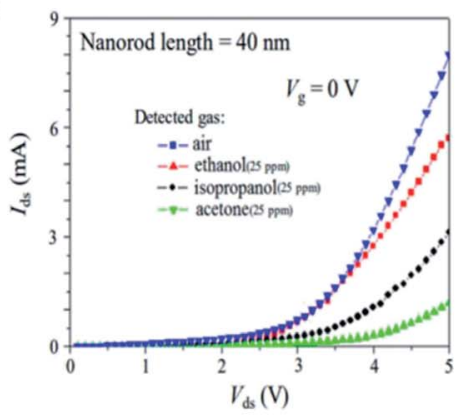

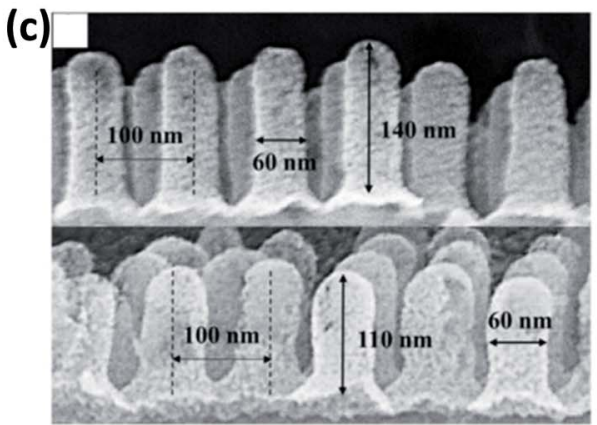

(f)

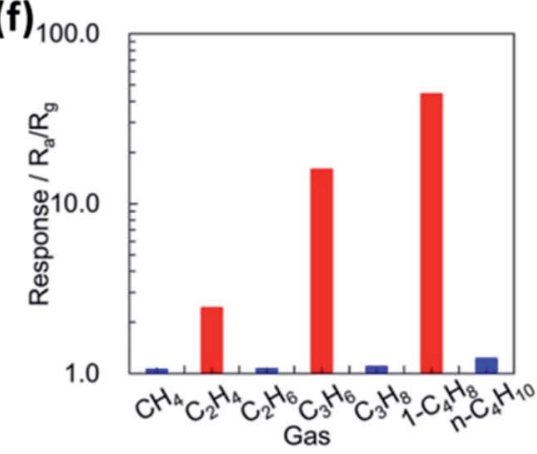

Fig. 6 (a) TEM images of $\mathrm{SnO}_{2}$ hollow nanotube and (b) its gas sensitivities to $\mathrm{NO}_{x}$ with concentration ranging between 9.7 ppm to 97 ppm at room temperature reproduced from ref. 97 with permission from Royal Society of Chemistry, Copyright 2021. (c) SEM images of different dimensions of $\mathrm{SnO}_{2}$ nanorod array, their electrical characteristics in the presence of air and $25 \mathrm{ppm}$ various disease biomarkers of (d) $340 \mathrm{~nm}$ and (e) $40 \mathrm{~nm} \mathrm{SnO} 2$ nanorod array adapted from ref. 91 with permission from American Chemical Society, Copyrights 2021. (f) Selectivity plot of SnO 2 nanosheets towards alkenes reproduced from ref. 92 with permission from American Chemical Society, Copyrights 2021. 
et al., where they studied the acetone, isopropanol and ethanol sensing properties of $\mathrm{SnO}_{2}$ nanorods at room temperature. They found the difference in sensing pattern with respect to the length of the synthesized nanorods shown in Fig. 6c-e.91 However, $\mathrm{SnO}_{2}$ nanosheets were found to be selective to ethane, propane and 1-butene compared to all other alkenes (Fig. 6f). ${ }^{92}$ Similarly, $\mathrm{WO}_{3}$ nanofiber exhibited a response of 4 , whereas nanowire showed a response of 2 to 1 ppm acetone. ${ }^{93}$ These distinct sensing performances of the same nanomaterial with different morphology were ascribed to the modifications in grain boundaries, porous nature and surface area for interaction sites.

Concurrently, the peculiar strategy of modulating the operating temperature for selectivity tuning towards a specific VOCs were studied. A SMO sensor operating at different temperature may behave like a distinct sensor with different performance to specific VOC. ${ }^{94-96}$ SENSOR Lab at Bresica (Italy) has addressed the issue of selectivity tuning by modulating the operating temperature of $\mathrm{ZnO}$ nanoparticles. They found the sensor was selective to $\mathrm{NO}_{2}$ at $300{ }^{\circ} \mathrm{C}, \mathrm{H}_{2}$ at $400{ }^{\circ} \mathrm{C}$ and $\mathrm{CH}_{4}$ at $500{ }^{\circ} \mathrm{C}$ and attributed to the thermodynamics of gas adsorption on the sensor surface including decomposition of gases on the surface. ${ }^{97}$ This strategy was also exhibited on the commercial sensors from Figaro Inc. ${ }^{98,99}$

Similarly, many other metal oxide nanostructure were utilized for sensing different biomarkers as listed in Table 2 by optimizing their morphology and operating temperature. The synergism between the optimization of morphology and operating temperature was explored in order to engineer the nanomaterial to selectively detect the biomarkers. Acetone was detected by $\mathrm{ZnO}$ nanomaterial with different morphologies such as flower shaped, brittle glass shaped and dandelion like spheres operated at $300{ }^{\circ} \mathrm{C}, 215{ }^{\circ} \mathrm{C}$ and $230{ }^{\circ} \mathrm{C} \cdot{ }^{\mathbf{1 0 0 , 1 0 1 , 1 0 3}} \mathrm{Yet}, \mathrm{ZnO}$ nanosheets showed high sensitivity to formaldehyde and acetaldehyde with a lower detection limit of $50 \mathrm{ppb}$ working at $220{ }^{\circ} \mathrm{C} .{ }^{102}$ Likewise, $\operatorname{In}_{2} \mathrm{O}_{3}$ nanowires detected acetone at $400{ }^{\circ} \mathrm{C}$, whereas thick wires detected low concentration (500 ppb) of $\mathrm{NO}_{2}$ at temperature less than $300{ }^{\circ} \mathrm{C} .{ }^{\mathbf{1 1 0}}$ Yet, $\mathrm{In}_{2} \mathrm{O}_{3}$ nanobricks detected $500 \mathrm{ppb}$ of $\mathrm{NO}_{2}$ at a significantly lower operating temperature of $50{ }^{\circ} \mathrm{C} .{ }^{112}$ These discussions illustrated the capability of tuning the selectivity by various optimization strategies. However, the response to exhaled concentration range tend to be poor due to lack in enhanced surface area for analyte interaction. In addition, meager conductivity of SMOs hinders the reproduction of the electrical change before and after analyte interaction to the outer world.

\subsection{D nanomaterials}

On the other hand, 2DMs has intriguing properties such as high surface area, high conductivity and high carrier mobility at room temperature with low noise that facilitates better response for target analytes. Exploiting these merits, graphene and its derivatives were the most explored carbon materials for gas sensor application in the past decade. The transparent and flexible characteristics of graphene were utilized for different configuration gas sensing devices. ${ }^{115-118}$ The defects induced by surface functionalization may influence the gas adsorption and desorption by the increase in number of reactive sites causing high sensitivity. Numerous review articles on graphene based gas sensors with a special focuses on its application in different fields, transduction principles, functionalization with metals and polymers were presented. ${ }^{\mathbf{1 1 9 - 1 2 6}}$

Table 2 The gas sensing performances of various SMOs with morphological optimization towards different diseases biomarkers in exhaled breath

\begin{tabular}{|c|c|c|c|c|c|c|}
\hline Materials & Nanostructure & Gas & Disease biomarker & Concentration & Sensor response & Ref. \\
\hline $\mathrm{ZnO}$ & 3D hierarchical flower & $\mathrm{C}_{3} \mathrm{H}_{6} \mathrm{O}$ & Diabetes & $100 \mathrm{ppm}$ & 18.6 & 100 \\
\hline $\mathrm{ZnO}$ & Brittle grass & $\mathrm{C}_{3} \mathrm{H}_{6} \mathrm{O}$ & Diabetes & $100 \mathrm{ppm}$ & 107 & 101 \\
\hline & & Acetaldehyde & & & $77 \%$ & \\
\hline $\mathrm{ZnO}$ & Dandelion like spheres & $\mathrm{C}_{3} \mathrm{H}_{6} \mathrm{O}$ & Diabetes & $100 \mathrm{ppm}$ & 33 & 103 \\
\hline $\mathrm{SnO}_{2}$ & Nanotubes & $\mathrm{NO}_{x}$ & Asthma & $9.7 \mathrm{ppb}$ & 16.1 & 90 \\
\hline & & Benzene & & & 1.5 & \\
\hline \multirow[t]{2}{*}{$\mathrm{SnO}_{2}$} & Flower-like nanostructures & Toluene & Lung cancer & $100 \mathrm{ppm}$ & 9.7 & 106 \\
\hline & & Formaldehyde & & & 9.5 & \\
\hline $\mathrm{WO}_{3}$ & Nanocolumns & $\mathrm{C}_{3} \mathrm{H}_{8} \mathrm{O}$ & & $100 \mathrm{ppm}$ & 3 & 107 \\
\hline $\mathrm{WO}_{3}$ & Nanoplate & $\mathrm{NO}_{2}$ & Asthma & $5 \mathrm{ppm}$ & 10 & 108 \\
\hline $\mathrm{WO}_{3}$ & Nanowire & $\mathrm{NH}_{3}$ & Renal failure & $300 \mathrm{ppm}$ & 2.39 & 109 \\
\hline & Nanosphere & & & & 1.62 & \\
\hline \multirow{3}{*}{$\mathrm{Co}_{3} \mathrm{O}_{4}$} & Nanosheet & $\mathrm{C}_{3} \mathrm{H}_{6} \mathrm{O}$ & Diabetes & $100 \mathrm{ppm}$ & 6.1 & 114 \\
\hline & Nanofiber & & & & 4.0 & \\
\hline & Nanorod & & & & 2.7 & \\
\hline
\end{tabular}


Table 3 The gas sensing performances of TMDs towards different diseases biomarkers in exhaled breath

\begin{tabular}{|c|c|c|c|c|c|c|}
\hline Materials & Layer thickness & Gas & Disease biomarker & Concentration & Sensor response & Ref. \\
\hline \multirow{3}{*}{$\mathrm{MoS}_{2}$} & Atomic & $\mathrm{NO}_{2}$ & Asthma & $120 \mathrm{ppb}$ & $35 \%$ & 128 \\
\hline & 1 & TEA & & $1 \mathrm{ppm}$ & $3 \%$ & 129 \\
\hline & 2 & NO & Asthma & $2 \mathrm{ppm}$ & $80 \%$ & 131 \\
\hline \multirow[t]{2}{*}{$\mathrm{WS}_{2}$} & $5 \mathrm{~nm}$ & $\mathrm{NO}_{2}$ & Asthma & $5 \mathrm{ppm}$ & $68.4 \%$ & 132 \\
\hline & $110 \mathrm{~nm}$ & $\mathrm{NH}_{3}$ & Renal failure & $5 \mathrm{ppm}$ & $1.6 \%$ & 133 \\
\hline & & $\mathrm{NO}_{2}$ & Asthma & $10 \mathrm{ppm}$ & $36.33 \%$ & 66 \\
\hline
\end{tabular}

Inspired by the physic-chemical and electrical properties of graphene derivatives favorable for gas sensing applications, researchers are exploring over the periodic table for the search of ultrathin 2DMs. Among them, 2DMs represented by $\mathrm{MX}_{2}$, where $\mathbf{M}$ denotes the transition metals like Mo, W, Hf, Ti, Zr, V, $\mathrm{Nb}, \mathrm{Ta}, \mathrm{Re}$, etc. and $\mathrm{X}$ denotes the chalcogens (Te, S or Se). ${ }^{127}$ However, only certain transition metal disulfides (TMDs) such as $\mathrm{MoS}_{2}, \mathrm{WS}_{2}$ and $\mathrm{SnS}_{2}$ have been utilized as a sensing film for the detection of various disease biomarkers in exhaled breath as listed in Table 3. In comparison with graphene (zero band gap), TMDs possess tunable bandgap (1-2 eV) with a shift from indirect to direct bandgap as a function of layer thickness due to exfoliation. ${ }^{\mathbf{1 3 6}}$ Among other chalcogens, TMDs are widely explored due to its abundant presence in nature, less toxic and stable in atmosphere compared to metal selenides and metal tellurides. Their gas sensing performances were illustrated in Fig. 7. The $\mathrm{NO}_{2}$ sensing performance of atomic layered $\mathrm{MoS}_{2}$ nanosheet at low concentration of $120 \mathrm{ppb}$ have not shown a complete recovery to the baseline and same occurrence was observed for subsequent concentrations (Fig. 7a). ${ }^{\mathbf{1 2 8}}$ Identically, monolayer graphene exhibited no recovery to the baseline at 12 ppm triethylamine (TEA) as shown in Fig. 7b. ${ }^{129}$ Similar performance was witnessed by $\mathrm{SnS}_{2}$ nanosheets with a high response $(\sim 170 \mathrm{~s})$ and recovery time $(\sim 140 \mathrm{~s})$ to $10 \mathrm{ppm} \mathrm{NO}_{2}$ (Fig. 7c). ${ }^{66}$ This is attributed to their layered structure possessing weak van der Waals interlayer force favorable for exfoliation down to single and multilayers. However, their strong molecular interlayer force causes restacking of the layer. ${ }^{\mathbf{1 3 7}}$ It is therefore desirable to composite them with a nanomaterial that acts as spacers which avoids restacking issues and facilitates porous structure for gas adsorption driven by high surface area, absorption coefficient and fast electron transfer. ${ }^{138}$

\subsection{SMOs/2DM nanocomposites}

The alternate approach of SMO/2DM binary nanocomposite may solve several challenges faced by standalone SMO or 2DM in enhancing the sensor performances in all the aspects. Their complementing features suitable for gas sensing applications are listed in Table 4 . The synergism favors electronic, chemical and geometrical effects of the sensing material. The combination of SMOs and 2DMs may rectify the restacking problems of the multilayer 2D sheets and facilitates porous structure for enhanced gas diffusion. Further, the depletion layer formed at the interface of $n-n, p-n$ or $p-p$ heterojunction modulates due to gas diffusion and may enhance charge transport along with the favorable chemical bonds formed between SMO and 2DM. ${ }^{139}$

As discussed in the previous section, $\mathrm{SnO}_{2}$ was widely used as a standalone material for gas sensors owing to its wide bandgap (3.6 eV). Moreover, its enhanced optical, electrical and electrochemical properties were suitable in various gas sensing device configurations. However, its capability of selectively (a)

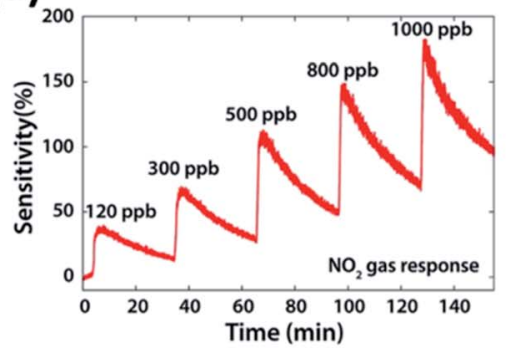

(b)

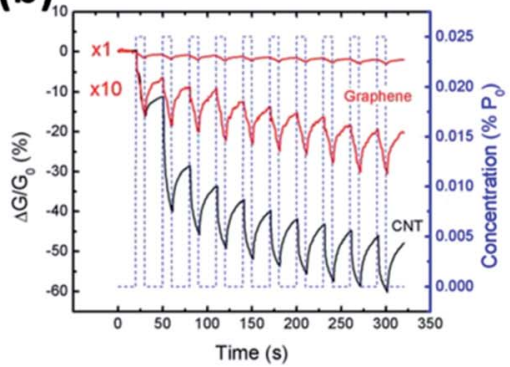

(c)

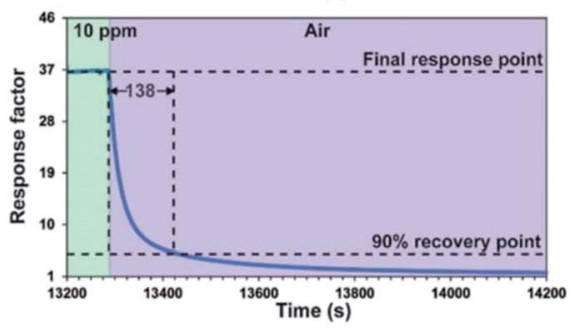

Fig. 7 (a) Transient response of atomic-layered $\mathrm{MoS}_{2}$ to $\mathrm{NO}_{2}$ with concentration ranging from $120 \mathrm{ppb}$ to $1000 \mathrm{ppb}$ operated at room temperature reproduced from ref. 128 with permission from American Chemical Society, Copyrights 2021 (b) conductivity change of monolayer graphene upon exposure to $12 \mathrm{ppm}$ TEA at room temperature reproduced from 129 with permission from American Chemical Society, Copyrights 2021 and (c) response/recovery of $\mathrm{SnS}_{2}$ to $10 \mathrm{ppm} \mathrm{NO}$ operated at $120{ }^{\circ} \mathrm{C}$ adopted from ref. 66 with permission from American Chemical Society, Copyrights 2021. 
Table 4 Complementing features of SMOs and TMDs

\begin{tabular}{lll}
\hline & Advantages & Disadvantages \\
\hline \multirow{2}{*}{ SMOs } & Scalable fabrication & Slow carrier transfer \\
& Low cost & $\begin{array}{l}\text { High operating } \\
\text { temperature }\end{array}$ \\
& Long-term stability & Lower gas response \\
TMDs & Fast carrier transfer & Sluggish recovery \\
& Low operating temperature & Low selectivity \\
& High gas response & Lack of stability
\end{tabular}

detecting gas concentration as low as in parts per billion among diverse environment was hindered for real time breath analysis application. Hence, numerous efforts have been made to composite it with 2DMs for the detection of variety of breath biomarkers under varying structural morphology of the nanocomposite and working conditions of the sensor. ${ }^{\mathbf{1 4 0}}$

Graphene- $\mathrm{SnO}_{2}$ nanocomposite showed selective sensing to $\mathrm{NO}_{2}$ at $150{ }^{\circ} \mathrm{C}$ achieving a lower detection limit of $1 \mathrm{ppm}$ with a response of 24.7 (Fig. 8a). ${ }^{\mathbf{1 4 1}}$ Meanwhile, Zhang et al. has showed that graphene- $\mathrm{SnO}_{2}$ nanocomposite was also selective for $\mathrm{H}_{2} \mathrm{~S}$ operated at $260{ }^{\circ} \mathrm{C}$ with a detection limit of $1 \mathrm{ppm}$ (Fig. 8b). ${ }^{\mathbf{1 4 2}}$ Further, $\mathrm{SnO}_{2}$ with various graphene derivatives was found to exhibit superior sensing performances detailed in our previous review. ${ }^{\mathbf{1 4 3}}$ Besides, composition of $\mathrm{SnO}_{2}$ with TMDs may elucidate peculiar properties due to synergism between them. The most widely used $\mathrm{MoS}_{2} / \mathrm{SnO}_{2} \mathrm{p}-\mathrm{n}$ heterojunction among other TMDs, demonstrated better sensing performances to TEA at an operating temperature of $230{ }^{\circ} \mathrm{C}$ (Fig. 8c). The performance of $\mathrm{Mo} / \mathrm{Sn}$ ratio of 0.53 dominated other mole ratios of the composite. The sensor showed a response of 24.9 for $100 \mathrm{ppm}$ of TEA with a detection limit of $5 \mathrm{ppm} .{ }^{\mathbf{1 4 4}}$ Meanwhile Han et al., investigated the detection of $\mathrm{NO}_{2}$ at room temperature by varying the $\mathrm{Mo} / \mathrm{Sn}$ molar ratio. The study revealed that $1.25 \mathrm{~mL}$ of stannic chloride with $20 \mathrm{~mL} \mathrm{MoS}$ nanosheet dispersion (MS-1.25) showed highest response of 18.7 to $5 \mathrm{ppm}$ $\mathrm{NO}_{2}$. Moreover the response time, complete recovery, long term stability and selectivity of the composite was significantly improved. The authors speculated the enlargement of surface area by the incorporation of $\mathrm{SnO}_{2}$ on $\mathrm{MoS}_{2}$ nanosheets and the $\mathrm{p}-\mathrm{n}$ heterojunction changed the electronic properties locally. ${ }^{\mathbf{1 4 5}}$ The humidity sensing property of $\mathrm{WS}_{2} / \mathrm{SnO}_{2}$ revealed the importance of 2DM/SMO composites, where a significant improvement in sensing performances (862.8 times) were observed compared to standalone SMO or 2DM. ${ }^{\mathbf{1 4 6}}$ Moreover, with much electronegative in nature, $\mathrm{SnS}_{2}$ was made composite with $\mathrm{SnO}_{2}$ to improve the selectivity towards ammonia and $\mathrm{NO}_{2} \cdot{ }^{147}$ The study by Li et al. showed significant selectivity to ammonia with a response of 2.48 for $100 \mathrm{ppm}$ at room temperature among other breath biomarkers (Fig. 8d). The sensor exhibited linear response at exhaled breath concentration range. ${ }^{\mathbf{1 4 7}}$ However, Ou et al., has established a strong (a)

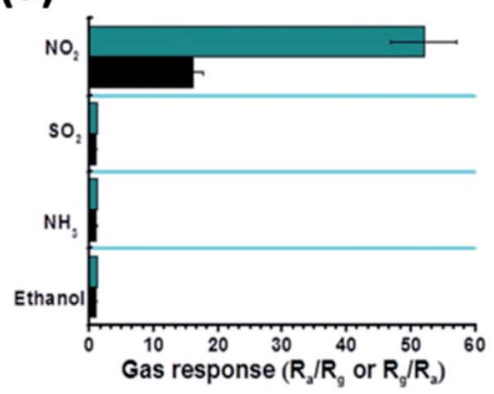

(d)

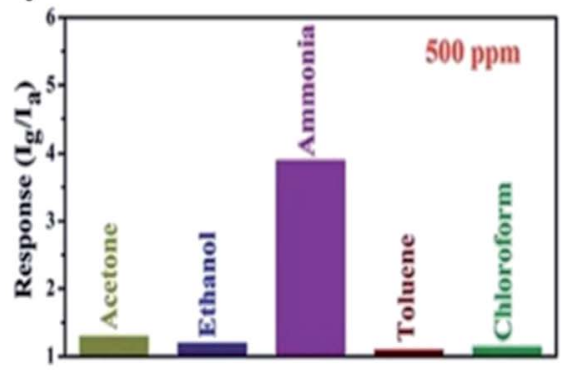

(b)

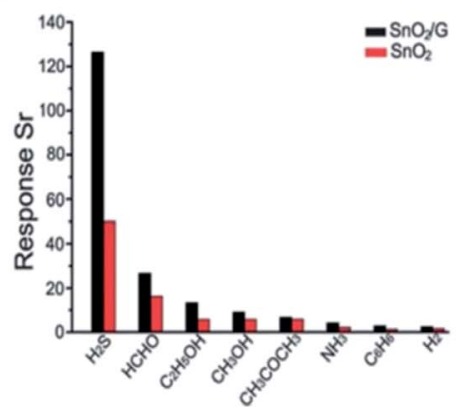

(e)

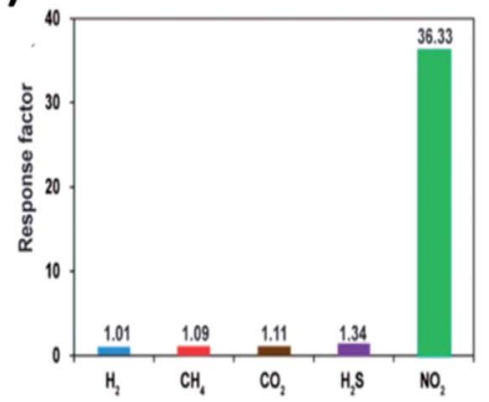

(c)

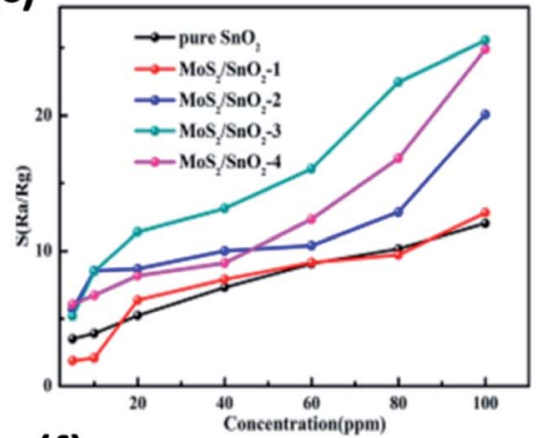

(f)

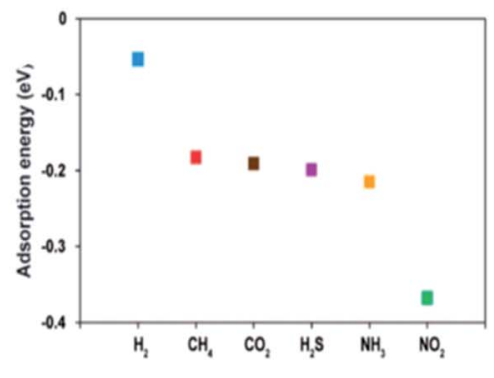

Fig. 8 Selectivity of (a) graphene- $\mathrm{SnO}_{2}$ binary nanocomposite to $3 \mathrm{ppm} \mathrm{NO}$ at $150{ }^{\circ} \mathrm{C}$ reproduced from ref. 141 with permission from American

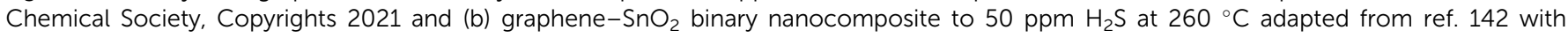
permission from Royal Society of Chemistry, Copyrights 2021. (c) Response of different Mo/Sn molar concentration of $\mathrm{MoS}_{2} / \mathrm{SnO}_{2}$ sensor to varying concentration (5-100 ppm) of TEA at an operating temperature of $280^{\circ} \mathrm{C}$ used from ref. 144 with permission from American Chemical Society, Copyrights 2021. (d) Selectivity characteristics of $\mathrm{SnO}_{2} / \mathrm{SnS}_{2}$ nanocomposite sensor to 500 ppm of ammonia and various gases at room temperature adapted from ref. 147 with permission from Royal Society of Chemistry, Copyrights 2021. (e) Response of SnS 2 sensor to various biomarkers at $160{ }^{\circ} \mathrm{C}$, (f) surface adsorption energy of $\mathrm{SnS}_{2}$ with studied biomarkers adapted from ref. 66 with permission from American Chemical Society, Copyrights 2021. 
Table 5 The gas sensing performances of various SMO/TMD nanocomposites towards different diseases biomarkers in exhaled breath

\begin{tabular}{|c|c|c|c|c|c|c|}
\hline SMO & $2 \mathrm{DM}$ & Gas & Disease & Concentration & Response & Ref. \\
\hline \multirow[t]{11}{*}{$\mathrm{SnO}_{2}$} & \multirow[t]{2}{*}{ Graphene } & $\mathrm{NO}_{2}$ & Asthma & 5 ppm & $72.6\left(R_{\mathrm{g}} / R_{\mathrm{a}}\right)$ & 141 \\
\hline & & $\mathrm{H}_{2} \mathrm{~S}$ & Halitosis & $50 \mathrm{ppm}$ & $130\left(R_{\mathrm{a}} / R_{\mathrm{g}}\right)$ & 142 \\
\hline & \multirow[t]{2}{*}{ Reduced graphene oxide } & $\mathrm{NH}_{3}$ & Renal failure & $1000 \mathrm{ppm}$ & - & 148 \\
\hline & & $\mathrm{HCHO}$ & Lung cancer & $10 \mathrm{ppm}$ & 435 & 149 \\
\hline & \multirow[t]{4}{*}{$\mathrm{MoS}_{2}$} & TEA & & $100 \mathrm{ppm}$ & $24.9\left(R_{\mathrm{a}} / R_{\mathrm{g}}\right)$ & 144 \\
\hline & & $\mathrm{NO}_{2}$ & Asthma & $5 \mathrm{ppm}$ & $18.7\left(G_{\mathrm{g}} / G_{\mathrm{a}}\right)$ & 145 \\
\hline & & $\mathrm{CH}_{4}$ & & $100 \mathrm{ppm}$ & 2.014 & 150 \\
\hline & & $\mathrm{NH}_{3}$ & Renal failure & $50 \mathrm{ppm}$ & $10 \%$ & 151 \\
\hline & $\mathrm{WS}_{2}$ & Humidity & & $95 \% \mathrm{RH}$ & $8.5\left(R_{\mathrm{a}} / R_{\mathrm{g}}\right)$ & 152 \\
\hline & \multirow[t]{2}{*}{$\mathrm{SnS}_{2}$} & $\mathrm{NH}_{3}$ & Renal failure & $100 \mathrm{ppm}$ & $2.48\left(I_{\mathrm{g}} / I_{\mathrm{a}}\right)$ & 147 \\
\hline & & $\mathrm{NO}_{2}$ & Asthma & $10 \mathrm{ppm}$ & 36.33 & 66 \\
\hline \multirow[t]{5}{*}{$\mathrm{ZnO}$} & Reduced graphene oxide & $\mathrm{NO}_{2}$ & Asthma & $0.5 \mathrm{ppm}$ & $12\left(R_{\mathrm{g}} / R_{\mathrm{a}}\right)$ & 153 \\
\hline & \multirow[t]{4}{*}{$\mathrm{MoS}_{2}$} & $\mathrm{C}_{3} \mathrm{H}_{6} \mathrm{O}$ & Diabetes & 5 ppm & $14.40\left(R_{\mathrm{a}} / R_{\mathrm{g}}\right)$ & 154 \\
\hline & & $\mathrm{NH}_{3}$ & Renal failure & $100 \mathrm{ppm}$ & $61.92 \%$ & 155 \\
\hline & & $\mathrm{NO}_{2}$ & Asthma & 50 ppm & $31.2 \%$ & 156 \\
\hline & & $\mathrm{C}_{2} \mathrm{H}_{5} \mathrm{OH}$ & Alcohol consumption & $50 \mathrm{ppm}$ & $42.8\left(R_{\mathrm{a}} / R_{\mathrm{g}}\right)$ & 157 \\
\hline \multirow[t]{4}{*}{$\mathrm{WO}_{3}$} & \multirow[t]{3}{*}{ Graphene } & $\mathrm{H}_{2} \mathrm{~S}$ & Halitosis & 5 ppm & $65.5\left(R_{\mathrm{a}} / R_{\mathrm{g}}\right)$ & 158 \\
\hline & & $\mathrm{C}_{3} \mathrm{H}_{6} \mathrm{O}$ & Diabetes & 5 ppm & $13.7\left(R_{\mathrm{a}} / R_{\mathrm{g}}\right)$ & \\
\hline & & $\mathrm{NO}_{2}$ & Asthma & 5 ppm & $133\left(R_{\mathrm{g}} / R_{\mathrm{a}}\right)$ & 159 \\
\hline & $\mathrm{MoS}_{2}$ & $\mathrm{H}_{2} \mathrm{~S}$ & Halitosis & $25 \mathrm{ppm}$ & $20 \%$ & 160 \\
\hline \multirow[t]{3}{*}{$\mathrm{TiO}_{2}$} & Reduced graphene oxide & Methanol & & $800 \mathrm{ppm}$ & $96.3 \%$ & 161 \\
\hline & $\mathrm{MoS}_{2}$ & $\mathrm{C}_{2} \mathrm{H}_{5} \mathrm{OH}$ & Alcohol consumption & $100 \mathrm{ppm}$ & 14.2 & 162 \\
\hline & $\mathrm{WS}_{2}$ & $\mathrm{NH}_{3}$ & Renal failure & $500 \mathrm{ppm}$ & 56.69 & 163 \\
\hline $\mathrm{Fe}_{2} \mathrm{O}_{3}$ & Reduced graphene oxide & $\mathrm{H}_{2} \mathrm{~S}$ & Halitosis & 1 ppm & 9.2 & 164 \\
\hline \multirow[t]{2}{*}{$\mathrm{Co}_{3} \mathrm{O}_{4}$} & Graphene oxide & $\mathrm{C}_{3} \mathrm{H}_{6} \mathrm{O}$ & Diabetes & 5 & $2.29\left(R_{\mathrm{g}} / R_{\mathrm{a}}\right)$ & 165 \\
\hline & $\mathrm{MoS}_{2}$ & $\mathrm{NH}_{3}$ & Renal failure & 0.1 & $10.3 \%$ & 166 \\
\hline $\mathrm{Cu}_{2} \mathrm{O}$ & Graphene & $\mathrm{H}_{2} \mathrm{~S}$ & Halitosis & $100 \mathrm{ppb}$ & $36 \%$ & 167 \\
\hline
\end{tabular}

detection of $\mathrm{NO}_{2}$ by $\mathrm{SnS}_{2}$ at lower operating temperature of $160{ }^{\circ} \mathrm{C}$ compared to other VOCs (Fig. 8e) and capable of detecting as low concentration as $0.6 \mathrm{ppm}$. They found the high selectivity of $\mathrm{NO}_{2}$ at $160{ }^{\circ} \mathrm{C}$ due to the lower adsorption energy of $\mathrm{NO}_{2}$ to $\mathrm{SnS}_{2}$ as shown in Fig. 8 . $^{66}$

Similarly, many other combinations of SMO/2DM were exploited for the detection of various exhaled biomarkers listed in Table 5 by various optimization strategies. Yan et al., has investigated the sensing performance of $\mathrm{ZnO}$ coated $\mathrm{MoS}_{2}$ to ethanol concentration ranging between 50-1000 ppm at an operating temperature of $260{ }^{\circ} \mathrm{C}$. Their results suggested the remarkable sensing behavior of $\mathrm{ZnO} @ \mathrm{MoS}_{2}$ binary metal oxide nanocomposite compared to pure $\mathrm{ZnO}$ in terms of sensitivity and selectivity to ethanol (Fig. 9a and b). These results are attributed to the development of interface at the heterojunction leading to rapid electron transfer by the direct conduction paths provided by $\mathrm{MoS}_{2}{ }^{157}$ Following this finding, Zhao et al., optimized the layer thickness of $\mathrm{MoS}_{2}$ on $\mathrm{ZnO}$ nanowires by varying the sputtering time to investigate $\mathrm{NO}_{2}$ sensing behavior at $200{ }^{\circ} \mathrm{C}$. The sensor exhibited excellent sensitivity with a detection limit of $200 \mathrm{ppb}$ favorable for breath analysis (Fig. 9c). Furthermore the sensor showed good selectivity to $50 \mathrm{ppm}$ of $\mathrm{NO}_{2}$ in comparison with the same concentration of $\mathrm{NH}_{3}, \mathrm{CO}_{2}$ and $\mathrm{CO}$ along with stable recovery and repeatability (Fig. $9 \mathrm{~d}) .{ }^{\mathbf{1 5 6}}$ Meanwhile, Qin et al. has hybridized $\mathrm{TiO}_{2}$ with $\mathrm{WS}_{2}$ with different molar ratio ( 0.44 to 1.65$)$ to improve the selectivity of $\mathrm{WS}_{2}$ 2DM towards ammonia at room temperature. The composite with a molar ratio of $0.44 \mathrm{TiO}_{2} \mathrm{QD} / \mathrm{WS}_{2}$ exhibited fast response and high selectivity to $500 \mathrm{ppm}$ ammonia. ${ }^{163}$
Furthermore, tungsten was also used in combination with $\mathrm{WS}_{2}$ to detect ammonia, $\mathrm{H}_{2}$ and $\mathrm{NO}_{2}$. They optimized the working temperature at $150{ }^{\circ} \mathrm{C}$ and achieved a lower detection limit of $1 \mathrm{ppm}$ to ammonia. ${ }^{168}$ These discussions provide a notion that different combination of SMO/2DMs with varying optimization strategies such as morphology, nanosheet's layer thickness and operating temperature would tune the sensing system towards specific biomarker with enhanced sensitivity. Similarly many other binary and ternary nanocomposites with 2DMs can be explored for elucidating the peculiar properties and explore them for the detection of various breath biomarkers. Incorporation of these sensors in handheld portable breath analyzer may possibly favor the underprivileged community in the poor healthcare resource setting. The biomarker concentration displayed on the system or rather transmitted wirelessly could pave way for universal use, for its effortless sample collection procedures. In the future, SMO/2DM based nanosensors could be miniaturized on a single lab-on-chip and could be used as a pocket device or an add-on to the mobile phones.

\section{Socio-economic demands and companies}

Nanosensors based on chemi-resistive principle for breath analysis has seen progress in recent years in terms of sensitive and selective detection of specific breath biomarkers amidst various interference including exogenous gases and humidity in breath. ${ }^{169-171}$ Meanwhile with low power demand resulting in 
(a)

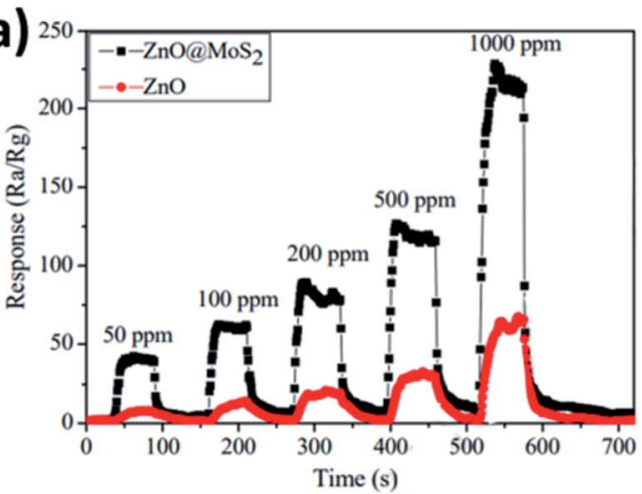

(c)

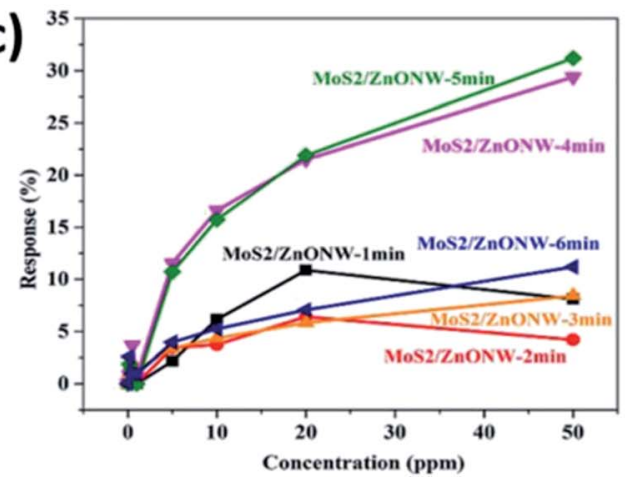

(b)

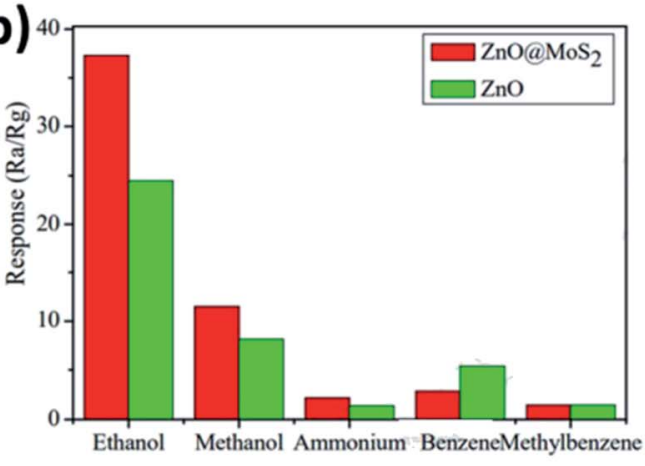

(d)

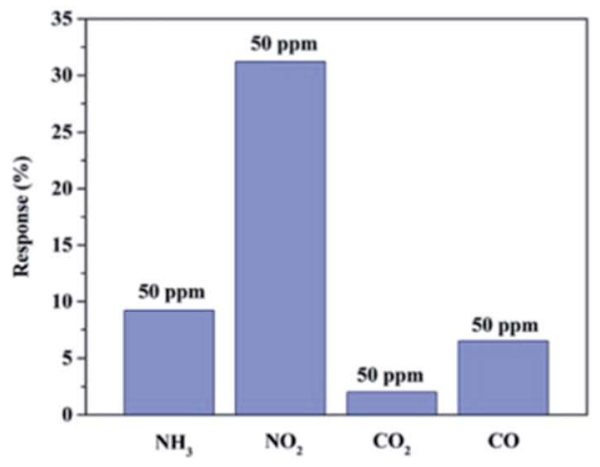

Fig. 9 (a) Typical response of $\mathrm{ZnO} @ \mathrm{MoS}_{2}$ to ethanol at concentration ranging between $50 \mathrm{ppm}$ to 1000 ppm operated at $260{ }^{\circ} \mathrm{C}$, (b) selectivity characteristics of $\mathrm{ZnO}\left(\mathrm{MoS}_{2}\right.$ to $100 \mathrm{ppm}$ ethanol at an operating temperature of $260{ }^{\circ} \mathrm{C}$ adopted from ref. 157 with permission from Elsevier, Copyrights 2021, (c) response of different sputtering time $\mathrm{MoS}_{2}$ on $\mathrm{ZnO}$ nanowires to varying concentrations of $\mathrm{NO}_{2}$ at $200{ }^{\circ} \mathrm{C}$ and (d) selectivity characteristics of $\mathrm{MoS}_{2} / \mathrm{ZnO}$ to $50 \mathrm{ppm} \mathrm{NO}$ at an operating temperature of $260{ }^{\circ} \mathrm{C}$ reproduced from ref. 156 with permission from Elsevier, Copyrights 2021.

Table 6 List of startups across the globe focusing on various disease diagnoses through breath analysis involving different technologies

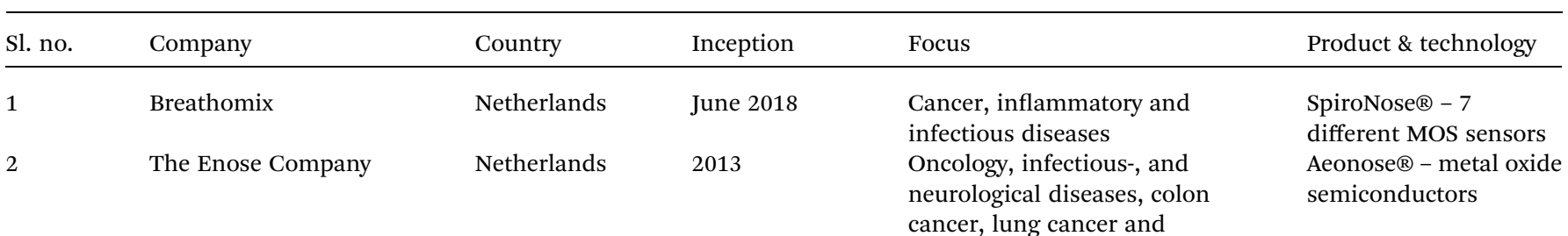

Breath Diagnostics Inc.

BreathDX

CAIRE Diagnostics

formerly Spirosure Inc.

Breath Analyzers Pte.

Ltd.

Algernon

Pharmaceuticals

formerly Breathtec

Biomedical Inc.

New England Breath

Technologies

Deep Breath Initiatives
US

UK

US

Singapore

2016

Canada

2015

UK

2018

Switzerland

2018 cancer, lung cancer and

tuberculosis

Liver disease, colon cancer and lung cancer

Lung cancer

Ammonia quantification

Allergic airway inflammation, conditions

Gastrointestinal diseases, helicobacteriosis

Liver disease - Non-Alcoholic Steato Hepatitis (NASH), chronic kidney disease and inflammatory bowel disease Type 2 diabetics asthma and other pulmonary

Field Asymmetric Ion Mobility Spectrometry (FAIMS)®

OneBreath $\AA$ - mass spectrometry AmBeR ${ }^{\circ}$ - nanosensors Fenom Pro® electrochemical

HepyScreen ${ }^{\circledR}$

$-$

Glucair®

Therapeutic drug monitoring

Mass spectrometry 
the reduction of device dimension on a single lab-on-chip, nanosensors are the choice of technology for incorporation in portable breathalyzers for disease diagnosis. Also, an array of cross-reactive nanosensors incorporated in the breathalyzer would mimic the mammalian olfactory and detect various gases emanating from breath probing the metabolic processes at the fundamental cellular levels favoring early detection of diseases. Accurate detection of these trace level gases would pave way for non-invasive, user friendly, personalized home care diagnostic equipment which lead to better control of diseases and monitor the effect of medication. Moreover, the instant display of results may avoid pre-analytical and post-analytical processes such as sample collection, preparation and test report dispatch. Also it enables mass screening during pandemic leading to reduced transmission rate of the disease. ${ }^{172}$ These processes eliminate consumables thus considerably reduce the global health expenditure. The merits of nanosensors create a demand for breathalyzers in global market demanding a socio-economic balance. Hence researchers across the globe are having high hopes and making strides on startups for disease diagnosis through breath analysis by various technologies. For instance, SpiroNose® developed by Breathomix utilizes 7 different SMO sensors that capture real-time breath profiles. The between-days repeatability of asthmatic and healthy subjects was precise and was even better when compared to the routine standard test (spirometry). ${ }^{173}$ Moreover, it satisfactorily discriminated healthy subjects and patients with COPD, asthma and lung cancer. ${ }^{174}$ Similarly, Aeonose ${ }^{\circledR}$ developed by The Enose Company, Netherlands have been found suitable for the prescreening of prostate, lung and collateral cancer proving it suitability for personalized home care. ${ }^{\mathbf{1 7 5 - 1 7 9}}$ Also, AmBeR® was designed and developed by BreathDX consists of an array of sensors fabricated by inkjet printing functional nanomaterials capable of ammonia measurement in ppb concentration range. ${ }^{\mathbf{1 8 0 , 1 8 1}}$ Each of the startup listed in Table 6 is focused on identifying various disease by fabricating a sensor selective to specific biomarkers and using other analytical technologies.

\section{Challenges and regulatory aspects}

Even though with the high socio-economic demand, inception of startups, research and development across the globe with the state-of-the-art technologies, there are numerous challenges needs to be addressed. For the commercial deployment of breathalyzer for non-invasive disease diagnosis in clinical setup and for personalized homecare utilization, much care must be provided in designing a nanomaterial based chemi-resistive sensor. Sensors should possess accurate detection capabilities as the breath sample is highly complex and informative due to the changes in breath volatolomics that occurs on the fundamental cellular processes. Moreover, the biomarker is in parts per million which demands the sensor to possess high sensitivity and selective to detect the trace level amount among other interfering biomarkers along with the strong influence of relative humidity in exhaled breath. Thus the sensor incorporated in breathalyzer should possess superior gas sensing performances such as sensitivity and selectivity towards specific disease biomarkers, humidity-resistive property, faster response and recovery time etc.

However, desiccants and pre-concentrators are crucially important, if the sensors do not satisfy the humidity-resistive property and selectivity, respectively. ${ }^{182}$ Moreover, as only the alveolar breath contains information about the cellular processes, the sensor chamber should be designed in such a way to accommodate the whole of alveolar breath and avoid sharp edges to eliminate recirculation zones. There is still no standardization on the collection of sample from either oral or nasal cavity. Hence, influence of exogenous production and presence of the biomarker as a pollutant in the atmosphere may hinder the exact quantification of endogenous production of biomarker.

More importantly, the biomarkers associated with specific diseases by the analytical techniques such as GC-MS is questionable as the pathophysiology of a single disease may diffuse numerous VOCs. Therefore, a global library of VOCs with corresponding diseases needs establishment to develop a cloud of breath database which may act as a reference standard. Further, the measuring electronics requires proper optimization to avoid instrumentation errors after proper breath sample collection and sensor design. The lack of standardization of library of VOCs, breath sample collection procedure, chamber design, sensor positioning and measuring electronics causes an insignificant criterion for reproducibility of the diagnostic outcomes. ${ }^{\mathbf{1 8 3 , 1 8 4}}$ The mentioned issues in standardization lead to huge variations in results between different studies and are hard to replicate. ${ }^{\mathbf{1 8 5}}$ Further, the sensors work in harsh environment (humidity and temperature) leading to eventual degradation in sensor performance. Hence, as there are opportunities and demand for a breathalyzer, corresponding challenges and improvements are necessary.

The use of nanomaterials for medical devices and implant materials has been successfully explored. Particularly in USA and Taiwan, nanomaterial incorporated products were widely seen that exhibits better performance compared to their bulk counterpart. However, safety and security being a primary concern, the considerable change in properties of the nanomaterial used in a medical device requires detailed study on their adverse effects on human body including toxicity. The dimensions of the nanoparticle decide its hazardous nature. Smaller particles may enter the human body through respiratory tract during inhalation, skin or oral ingestion due to the poor immune system of human body towards nanoparticle. For instance, nanoparticles less than $30 \mathrm{~nm}$ in size may damage the central nervous system, the defective mechanism of lung cells is not capable of handling nanoparticle with the size lesser than $70 \mathrm{~nm}$ and nanoparticle size less than $50 \mathrm{~nm}$ may enter the nucleus of human cells. ${ }^{\mathbf{1 8 6 , 1 8 7}}$

Hence, nanomaterial based medical devices have raised the concern for health authorities to develop certain regulatory aspects for safety assessment that does not develop any temporary or permanent discomfort to the users. The risks associated with the absorption or distribution of nanomaterial in human body must be established. Along with these safety assessments, no compromise in the quality must be ensured by 
the manufacturer by focusing on repeated validation on the manufactured nano medical device. ${ }^{188}$ Hence, regulatory requirements are good manufacturing procedures, labeling and warning, approval procedures and post market follow up.

\section{Conclusion and future outlooks}

Non-invasive disease diagnosis through breath analysis is one of the foreseen healthcare services. Their tendency to replicate the fundamental cellular process makes it more attractive for early diagnosis leading to the increases in survival by adopting effective treatment methodologies. To this direction, chemiresistive VOC sensors with a well understood sensing mechanisms for simple, fast and accurate detection of breath biomarkers were presented in this current review. These chemiresistive gas sensors possess miniaturization capabilities with no trade-off on the performance, which pose as a primary requirement for point-of-care medical devices. As mentioned in this review, numerous SMO nanostructures, 2D nanosheets and their composites have been utilized for the detection of various disease biomarkers. Their demonstrated performances were favorable for diagnosis of disease from exhaled breath with an easy sampling procedure and instant display of the outcome. Besides, their mass-screening competency during COVID-19 pandemic has found a new market for portable breathalyzers.

Whilst, the strength of the technology remains weak and inconclusive. This reflects the lack of standardization of breath sampling, sensor technologies and sample sizes across the spectrum of studies. Under-powering alongside difficulties including inference by numerous other external sources of VOCs and complexity of breath have both contributed to the setback of the technology for regular clinical trial. It seems that the implementation of gas sensors for breath analysis application has not reached the maturity for the widespread acceptance and usage. Nonetheless, SMO/2DM nanocomposites are amongst the few materials that enhance geometrical, chemical and electronic properties for gas sensing applications to tune its selective binding with a single biomarker at lower concentration. Further, placement of cross reactive sensors and coupling of breath sample to sensors through pre-concentrator devices on a single lab-on-chip may realize the dream of non-invasive disease diagnosis through breath analysis.

However, with the rapid advancements in the field of nanotechnology, regulatory aspect of these medical devices essentially takes care of all the relevant issues. The quality and safety of these devices must be enforced by the regulatory authorities in order to protect the manufacturing staffs and the end-users. Meanwhile, frequent updates are necessary with respect to the emerging applicability of nanomaterials and devices.

\section{Conflicts of interest}

The authors declare no conflict of interest, financial or otherwise.

\section{References}

1 S. Das, S. Pal and M. Mitra, Significance of Exhaled Breath Test in Clinical Diagnosis: A Special Focus on the Detection of Diabetes Mellitus, J. Med. Biol. Eng., 2016, 36, 605-624.

2 A. Mazzatenta, C. D. Giulio and M. Pokorski, Pathologies currently identified by exhaled biomarkers, Respir. Physiol. Neurobiol., 2013, 187, 128-134.

3 H. Kataoka, K. Saito, H. Kato and K. Masuda, Noninvasive analysis of volatile biomarkers in human emanations for health and early disease diagnosis, Bioanalysis, 2013, 5, 1443-1459.

4 L. Pauling, A. B. Robinson, R. Teranishi and P. Cary, Quantitative analysis of urine vapor and breath by gasliquid partition chromatography, Proc. Natl. Acad. Sci. U. S. A., 1971, 68, 2374-2376.

5 M. Beccaria, C. Bobak, B. Maitshotlo, T. R. Mellors, G. Purcaro, F. A. Franchina, C. A. Rees, M. Nasir, A. Black and J. E. Hill, Exhaled human breath analysis in active pulmonary tuberculosis diagnostics by comprehensive gas chromatography-mass spectrometry and chemometric techniques, J. Breath Res., 2018, 13, 016005.

6 M. J. Wilde, et al., Breath analysis by two-dimensional gas chromatography with dual flame ionisation and mass spectrometric detection - method optimisation and integration within a large-scale clinical study, $J$. Chromatogr. A, 2019, 1594, 160-172.

7 J. C. Soo, E. G. Lee, R. F. LeBouf, M. L. Kashon, W. Chisholm and M. Harper, Evaluation of a portable gas chromatograph with photoionization detector under variations of VOC concentration, temperature, and relative humidity, $J$. Occup. Environ. Hyg., 2018, 15, 351-360.

8 G. Qi, Q. Li, G. Liu, C. Qiu, T. Long and D. Tian, Design of a Resonant Radiofrequency Driver for Ion Transmission in a Desktop Mass Spectrometer and Its Application in Volatile Organic Compound Determination, Anal. Lett., 2020, 53, 1554-1565.

9 E. I. Schwarz, A. Engler and M. Kohler, Exhaled breath analysis in obstructive sleep apnea, Expert Rev. Respir. Med., 2017, 11, 631-639.

10 X. Wu, J. Zhang, X. Yan, Y. Zhu, W. Li, P. Li, H. Chen, W. Zhang, N. Cheng and T. Xiang, Characterization of Liver Failure by the Analysis of Exhaled Breath by Extractive Electrospray Ionization Mass Spectrometry (EESI-MS): A Pilot Study, Anal. Lett., 2020, 54, 1038-1054.

11 P. Finamore, S. Scarlata and R. A. Incalzi, Breath analysis in respiratory diseases: state-of-the-art and future perspectives, Expert Rev. Mol. Diagn., 2018, 19, 47-61.

$12 \mathrm{Z}$. Wang and C. Wang, Is breath acetone a biomarker of diabetes? A historical review on breath acetone measurements, J. Breath Res., 2013, 7, 037109.

13 H. Haick, Y. Y. Broza, P. Mochalski, V. Ruzsanyi and A. Amann, Assessment, origin, and implementation of breath volatile cancer markers, Chem. Soc. Rev., 2014, 43, 1423-1449. 
14 T. D. C. Minh, D. R. Blake and P. R. Galasetti, The clinical potential of exhaled breath analysis for diabetes mellitus, Diabetes Res. Clin. Pract., 2012, 97, 195-205.

15 T. A. Popov, Human exhaled breath analysis, Ann. Allergy, Asthma, Immunol., 2011, 106, 451-456.

16 H. Chen, X. Qi, J. Ma, C. Zhang, H. Feng and M. Yao, Breathborne VOC Biomarkers for COVID-19, medRxiv, 2020, DOI: 10.1101/2020.06.21.20136523.

17 S. Abdulla, T. L. Mathew and B. Pullithadathil, Highly sensitive, room temperature gas sensor based on polyaniline-multiwalled carbon nanotubes (PANI/ MWCNTs) nanocomposite for trace-level ammonia detection, Sens. Actuators, B, 2015, 221, 1523-1534.

18 C.-C. Chen, J.-C. Hsieh, C.-H. Chao, W.-S. Yang, H.-T. Cheng, C.-K. Chan and H.-W. Zan, Correlation between breath ammonia and blood urea nitrogen levels in chronic kidney disease and dialysis patients, J. Breath Res., 2020, 14, 036002.

19 D. Zhang, Z. Wu and X. Zong, Flexible and highly sensitive $\mathrm{H}_{2} \mathrm{~S}$ gas sensor based on in situ polymerized $\mathrm{SnO}_{2} / \mathrm{rGO} /$ PANI ternary nanocomposite with application in halitosis diagnosis, Sens. Actuators, B, 2019, 289, 32-41.

20 D. Feng, L. Du, X. Xing, C. Wang, J. Chen, Z. Zhu, Y. Tian and D. Yang, Highly Sensitive and Selective $\mathrm{NiO} / \mathrm{WO}_{3}$ Composite Nanoparticles in Detecting $\mathrm{H}_{2} \mathrm{~S}$ Biomarker of Halitosis, ACS Sens., 2021, 6, 733-741.

21 P. Singh, L. L. Hu, H.-W. Zan and T.-Y. Tseng, Highly sensitive nitric oxide gas sensor based on ZnO-nanorods vertical resistor operated at room temperature, Nanotechnology, 2018, 30, 095501.

22 D.-W. Jeong, K. H. Kim, B. S. Kim and Y. T. Byun, Characteristics of highly sensitive and selective nitric oxide gas sensors using defect-functionalized singlewalled carbon nanotubes at room temperature, Appl. Surf. Sci., 2021, 550, 149250.

23 S. P. Subin David, S. Veeralakshmi, J. Sandhya, S. Nehru and S. Kalaiselvam, Room temperature operatable high sensitive toluene gas sensor using chemiresistive $\mathrm{Ag} / \mathrm{Bi}_{2} \mathrm{O}_{3}$ nanocomposite, Sens. Actuators, B, 2020, 320, 128410.

24 Y. Xu, X. Tian, Y. Fan and Y. Sun, A formaldehyde gas sensor with improved gas response and sub-ppm level detection limit based on $\mathrm{NiO} / \mathrm{NiFe}_{2} \mathrm{O}_{4}$ composite nanotetrahedrons, Sens. Actuators, B, 2020, 309, 127719.

25 K. Yuan, C.-Y. Wang, L.-Y. Zhu, Q. Cao, J.-H. Yang, X.-X. Li and D. W. Zhang, Fabrication of a Micro-Electromechanical System-Based Acetone Gas Sensor Using $\mathrm{CeO}_{2}$ NanodotDecorated $\mathrm{WO}_{3}$ Nanowires, ACS Appl. Mater. Interfaces, 2020, 212, 14095-14104.

26 X. Zhang, B. Dong, W. Liu, X. Zhou, M. Liu, X. Sun, J. Lv, L. Zhang, W. Xu, X. Bai, L. Xu, S. Mintova and H. Song, Highly sensitive and selective acetone sensor based on three-dimensional ordered $\mathrm{WO}_{3} / \mathrm{Au}$ nanocomposite with enhanced performance, Sens. Actuators, B, 2020, 320, 128405.

27 K.-S. Choi, S. Kondaveeti and B. Min, Bioelectrochemical methane $\left(\mathrm{CH}_{4}\right)$ production in anaerobic digestion at different supplemental voltages, Bioresour. Technol., 2017, 245, 826-832.

28 D. Dong, P. Aleta, X. Zhao, O. K. Choi, S. Kim and J. W. Lee, Effects of nanoscale zero valent iron (nZVI) concentration on the biochemical conversion of gaseous carbon dioxide $\left(\mathrm{CO}_{2}\right)$ into methane $\left(\mathrm{CH}_{4}\right)$, Bioresour. Technol., 2019, 275, 314-320.

29 T. Arakawa, T. Suzuki, M. Tsujii, K. Iitani, P.-J. Chien, M. Ye, K. Toma, Y. Iwasaki and K. Mitsubayashi, Real-time monitoring of skin ethanol gas by a high-sensitivity gas phase biosensor (bio-sniffer) for the non-invasive evaluation of volatile blood compounds, Biosens. Bioelectron., 2019, 129, 245-253.

30 R. Sha, S. K. Puttapati, V. V. S. S. Srikanth and S. Badhulika, Ultra-Sensitive Non-Enzymatic Ethanol Sensor Based on Reduced Graphene Oxide-Zinc Oxide Composite Modified Electrode, IEEE Sens. J., 2018, 18, 1844-1848.

31 G. Peng, M. Hakim, Y. Y. Broza, S. Billan, R. AbdahBortnyak, A. Kuten, U. Tisch and H. Haick, Detection of lung, breast, colorectal, and prostate cancers from exhaled breath using a single array of nanosensors, $\mathrm{Br}$. J. Cancer, 2010, 103, 542-551.

32 M. Marom, F. Nakhoul, U. Tisch, A. Shiban, Z. Abassi and H. Haick, Gold nanoparticle sensors for detecting chronic kidney disease and disease progression, Nanomedicine, 2012, 7, 639-650.

33 G. Konvalina and H. Haick, Sensors for breath testing: from nanomaterials to comprehensive disease detection, Acc. Chem. Res., 2014, 47, 66-76.

34 O. Lawal, W. M. Ahmed, T. M. E. Nijsen, R. Goodacre and S. J. Fowler, Exhaled breath analysis: a review of 'breathtaking' methods for off-line analysis, Metabolomics, 2017, 13, 110.

35 M. D. Davis, S. J. Fowler and A. J. Montpetit, Exhaled breath testing - a tool for the clinician and researcher, Paediatr. Respir. Rev., 2019, 29, 37-41.

36 R. Einoch Amor, M. K. Nakhleh, O. Barash and H. Haick, Breath analysis of cancer in the present and the future, Eur. Respir. Rev., 2019, 28, 190002.

37 H. Haick, Y. Y. Broza, P. Mochalski, V. Ruzsanyi and A. Amann, Assessment, origin, and implementation of breath volatile cancer markers, Chem. Soc. Rev., 2014, 43, 1423-1449.

38 X. Zhou, Z. Xue, X.-Y. Chen, C. Huang, W. Bai, Z. Lu and T. Wang, Nanomaterial-based gas sensors used for breath diagnosis, J. Mater. Chem., 2020, 8, 3231-3248.

39 R. Einoch Amor, M. K. Nakhleh, O. Barash and H. Haick, Breath analysis of cancer in the present and the future, Eur. Respir. Rev., 2019, 28, 190002.

40 H. Haick, Y. Y. Broza, P. Mochalski, V. Ruzsanyi and A. Amann, Assessment, origin, and implementation of breath volatile cancer markers, Chem. Soc. Rev., 2014, 43, 1423-1449.

41 X. Zhou, Z. Xue, X.-Y. Chen, C. Huang, W. Bai, Z. Lu and T. Wang, Nanomaterial-based gas sensors used for breath diagnosis, J. Mater. Chem., 2020, 8, 3231-3248. 
42 T. Mathew, P. Pownraj, S. Abdulla and B. Pullithadathil, Technologies for Clinical Diagnosis Using Expired Human Breath Analysis, Diagnostics, 2015, 5, 27-60.

43 J. E. Fitzgerald, E. T. H. Bui, N. M. Simon and H. Fenniri, Artificial Nose Technology: Status and Prospects in Diagnostics, Trends Biotechnol., 2017, 35, 33-42.

44 M. P. Hlastala, The alcohol breath test - a review, J. Appl. Physiol., 1998, 84, 401-408.

45 L. E. Gustafsson, A. M. Leone, M. G. Persson, N. P. Wiklund and S. Moncada, Endogenous Nitric Oxide Is Present in the Exhaled Air of Rabbits, Guinea Pigs and Humans, Biochem. Biophys. Res. Commun., 1991, 181, 852-857.

46 R. A. Dweik, P. B. Boggs, S. C. Erzurum, C. G. Irvin, M. W. Leigh, J. O. Lundberg, A. C. Olin, A. L. Plummer and D. R. Taylor, American Thoracic Society Committee on Interpretation of Exhaled Nitric Oxide Levels for Clinical, A. An Official Ats Clinical Practice Guideline: Interpretation of Exhaled Nitric Oxide Levels (Feno) for Clinical Applications, Am. J. Respir. Crit. Care Med., 2011, 184, 602-615.

47 M. Simren and P. O. Stotzer, Use and Abuse of Hydrogen Breath Tests, Gut, 2006, 55, 297-303.

48 J. Romagnuolo, D. Schiller and R. J. Bailey, Using Breath Tests Wisely in a Gastroenterology Practice: An EvidenceBased Review of Indications and Pitfalls in Interpretation, Am. J. Gastroenterol., 2002, 97, 1113-1126.

49 M. Masikini, M. Chowdhury and O. Nemraoui, ReviewMetal Oxides: Application in Exhaled Breath Acetone Chemiresistive Sensors, J. Electrochem. Soc., 2020, 167, 037537.

50 S. Bhatia, N. Verma and R. K. Bedi, Ethanol gas sensor based upon $\mathrm{ZnO}$ nanoparticles prepared by different techniques, Results Phys., 2017, 7, 801-806.

51 H. Yan, P. Song, S. Zhang, J. Zhang, Z. Yang and Q. Wang, A low temperature gas sensor based on Au-loaded $\mathrm{MoS}_{2}$ hierarchical nanostructures for detecting ammonia, Ceram. Int., 2016, 42, 9327-9331.

52 Y. Al-Hadeethi, A. Umar, A. A. Ibrahim, S. H. Al-Heniti, R. Kumar, S. Baskoutas and B. M. Raffah, Synthesis, characterization and acetone gas sensing applications of Ag-doped ZnO nanoneedles, Ceram. Int., 2017, 43, 67656770.

53 S. P. Patil, V. L. Patil, S. S. Shendage, N. S. Harale, S. A. Vanalakar, J. H. Kim and P. S. Patil, Spray pyrolyzed indium oxide thick films as $\mathrm{NO}_{2}$ gas sensor, Ceram. Int., 2016, 43, 16160-16168.

54 R. Kalidoss, S. Umapathy and Y. Sivalingam, An Investigation of $\mathrm{GO}-\mathrm{SnO}_{2}-\mathrm{TiO}_{2}$ Ternary Nanocomposite for the Detection of Acetone in Diabetes Mellitus Patient's Breath, Appl. Surf. Sci., 2018, 449, 677-684.

55 M. Righettoni, A. Tricoli and S. E. Pratsinis, $\mathrm{Si}: \mathrm{WO}_{3}$ Sensors for highly selective detection of acetone for easy diagnosis of diabetes by breath analysis, Anal. Chem., 2010, 82, 3581-3587.

56 D. Liu, L. Lin, Q. Chen, H. Zhou and J. Wu, Low Power Consumption Gas Sensor Created from Silicon
Nanowires/ $/ \mathrm{TiO}_{2}$ Core-Shell Heterojunctions, ACS Sens., 2017, 2, 1491-1497.

57 N. Sharma, H. S. Kushwah, S. K. Sharma and K. Sachdev, Fabrication of $\mathrm{LaFeO}_{3}$ and $\mathrm{rGO}_{\mathrm{LaFeO}}$ microspheres based gas sensors for detection of $\mathrm{NO}_{2}$ and CO, RSC Adv., 2020, 10, 1297-1308.

58 A. Bag and N. E. Lee, Gas sensing with heterostructures based on two-dimensional nanostructured materials: a review, J. Mater. Chem. C, 2019, 7, 13367-13383.

59 G. F. Fine and L. M. Cavanagh, Metal Oxide SemiConductor Gas Sensors in Environmental Monitoring, Sensors, 2010, 10, 5469-5502.

60 M. Gardon and J. M. Guilemany, A review on fabrication, sensing mechanisms and performance of metal oxide gas sensors, J. Mater. Sci.: Mater. Electron., 2013, 24, 1410-1421.

61 Y. F. Sun, S. B. Liu, F. L. Meng, J. Y. Liu, Z. Jin, L. T. Kong and J. H. Liu, Metal Oxide Nanostructures and Their Gas Sensing Properties: A Review, Sensors, 2012, 12, 2610-2631.

62 X. Liu, S. Cheng, H. Liu, S. Hu, D. Zhang and H. Ning, A Survey on Gas Sensing Technology, Sensors, 2012, 12, 9635-9665.

63 F. Sarf, Gas Sensors: Metal Oxide Gas Sensors by Nanostructures, Intech open, 2019, DOI: 10.5772/ intechopen.88858.

64 G. Lee, S. Kim, S. Jung and J. Kim, Suspended black phosphorus nanosheet gas sensors, Sens. Actuators, B, 2017, 250, 569-573.

65 Q. Yue, Z. Shao, S. Chang and J. Li, Adsorption of gas molecules on monolayer $\mathrm{MoS}_{2}$ and effect of applied electric field, Nanoscale Res. Lett., 2013, 8, 425.

66 J. Z. Ou, et al., Physisorption-Based Charge Transfer in TwoDimensional $\mathrm{SnS}_{2}$ for Selective and Reversible $\mathrm{NO}_{2}$ Gas Sensing, ACS Nano, 2015, 9, 10313-10323.

67 R. Kalidoss, S. Umapathy, R. Anandan, V. Ganesh and Y. Sivalingam, Comparative Study on the Preparation and Gas Sensing Properties of Reduced Graphene Oxide/ $\mathrm{SnO}_{2}$ Binary Nanocomposite for Detection of Acetone in Exhaled Breath, Anal. Chem., 2019, 91, 5116-5124.

68 C. Wang, L. Yin, L. Zhang, D. Xiang and R. Gao, Metal Oxide Gas Sensors: Sensitivity and Influencing Factors, Sensors, 2010, 10, 2088-2106.

69 G. Peng, U. Tisch, O. Adams, M. Hakkim, N. Shehada, Y. Y. Broza, S. Billan, R. A. Bortnyak, A. Kuten and H. Haick, Diagnosing lung cancer in exhaled breath using gold nanoparticles, Nat. Nanotechnol., 2009, 4, 669-673.

70 T. P. J. Blaikie, J. Couper, G. Hancock, P. L. Hurst, R. Peverall, G. Richmond, G. A. D. Ritchie, D. Taylor and K. Valentine, Portable device for measuring breath acetone based on sample preconcentration and cavity enhanced spectroscopy, Anal. Chem., 2016, 88, 1101611021.

71 M. Sun, Z. Wang, Y. Yuan, Z. Chen, X. Zhao, Y. Li and C. Wang, Continuous monitoring of breath acetone, blood glucose and blood ketone in 20 type 1 diabetic outpatients over 30 days, J. Anal. Bioanal. Tech., 2017, 8, 386.

72 P. Gouma, K. Kalyanasundaram, X. Yun, M. Stanaćević and L. Wang, Nanosensor and breath analyzer for ammonia 
detection in exhaled human breath, IEEE Sens. J., 2010, 10, 49-53.

73 L. Wang, K. Kalyanasundaram, M. Stanaćević and P. Gouma, Nanosensor device for breath acetone detection, Sens. Lett., 2010, 8, 1-4.

74 P. Gouma, S. Sood, M. Stanaćević and S. Simon, Selective chemosensing and diagnostic breathanalyzer, Procedia Eng., 2014, 87, 9-15.

75 P. Gouma, A. Prasad and M. Stanaćević, Selective nanosensor device for exhaled breath analysis, J. Breath Res., 2011, 5, 037110.

76 P. Gouma, Interview: revolutionizing personalized medicine with nanosensor technology, Pers. Med., 2011, 8, 15-16.

77 P. Gouma and M. Stanaćević, Selective nanosensor array microsystem for exhaled breath analysis, Procedia Eng., 2011, 25, 1557-1560.

78 P. Gouma and S. Sood, 3-sensor array for hand held breath diagnostic tool, MRS Online Proc. Libr., 2013, 1553.

79 M. Righettoni, A. Amann and S. E. Pratsinis, Breath analysis by nanostructured metal oxides as chemo-resistive gas sensors, Mater. Today, 2015, 18, 163-171.

80 N. Nasiri and C. Clarke, Nanostructured Gas Sensors for Medical and Health Applications: Low to High Dimensional Materials, Biosensors, 2019, 9, 43.

81 N. Nasiri and C. Clarke, Nanostructured Chemiresistive Gas Sensors for Medical Applications, Sensors, 2019, 19, 462.

82 G. Neri, First Fifty Years of Chemoresistive Gas Sensors, Chemosensors, 2015, 3, 1-20.

83 H.-R. Kim, K.-I. Choi, K.-M. Kim, I.-D. Kim, G. Cao and J.-H. Lee, Ultra-fast responding and recovering $\mathrm{C}_{2} \mathrm{H}_{5} \mathrm{OH}$ sensors using $\mathrm{SnO}_{2}$ hollow spheres prepared and activated by Ni templates, Chem. Commun., 2010, 46, 5061.

84 Y. Zhang, Y. Liu, L. Zhou, D. Liu, F. Liu, F. Liu, X. Liang, X. Yan, Y. Gao and G. Lu, The role of Ce doping in enhancing sensing performance of ZnO-based gas sensor by adjusting the proportion of oxygen species, Sens. Actuators, B, 2018, 273, 991-998.

85 A. J. Kulandaisamy, C. Karthek, P. Shankar, G. K. Mani and J. B. Balaguru Rayappan, Tuning selectivity through cobalt doping in spray pyrolysis deposited $\mathrm{ZnO}$ thin films, Ceram. Int., 2016, 1408-1415.

86 P. Zhu, F. Song, P. Ma, Y. Wang, C. Chen and J. Feng, Morphology-controlled self-assembly of a ferroceneporphyrin based $\mathrm{NO}_{2}$ gas sensor: tuning the semiconducting nature via solvent-solute interaction, $J$. Mater. Chem. C, 2016, 4, 10471-10478.

87 I. Paulowicz, V. Hrkac, S. Kaps, V. Cretu, O. Lupan, T. Braniste, V. Duppel, I. Tiginyanu, L. Kienle, R. Adelung and Y. K. Mishra, Three-Dimensional $\mathrm{SnO}_{2}$ Nanowire Networks for Multifunctional Applications: From HighTemperature Stretchable Ceramics to Ultraresponsive Sensors, Adv. Electron. Mater., 2015, 1, 1500081.

88 S. Kaps, S. Bhowmick, J. Gröttrup, V. Hrkac, D. Stauffer, H. Guo, O. L. Warren, J. Adam, L. Kienle, A. M. Minor, R. Adelung and Y. K. Mishra, Piezoresistive Response of
Quasi-One-Dimensional ZnO Nanowires Using an in situ Electromechanical Device, ACS Omega, 2017, 2, 2985-2993.

89 A. Dey, Semiconductor metal oxide gas sensors: a review, Mater. Sci. Eng., B, 2018, 229, 206-217.

90 C. Jiang, G. Zhang, Y. Wu, L. Li and K. Shi, Facile synthesis of $\mathrm{SnO}_{2}$ nanocrystalline tubes by electrospinning and their fast response and high sensitivity to $\mathrm{NO}_{\mathrm{x}}$ at room temperature, CrystEngComm, 2012, 14, 2739.

91 S. Xu, H. Zhao, Y. Xu, R. Xu and Y. Lei, Carrier MobilityDominated Gas Sensing: A Room-Temperature GasSensing Mode for $\mathrm{SnO}_{2}$ Nanorod Array Sensors, ACS Appl. Mater. Interfaces, 2018, 10, 13895-13902.

92 P. G. Choi, N. Izu, N. Shirahata and Y. Masuda, $\mathrm{SnO}_{2}$ Nanosheets for Selective Alkene Gas Sensing, ACS Appl. Nano Mater., 2019, 2, 1820-1827.

93 S. Wei, G. Zhao, W. Du and Q. Tian, Synthesis and excellent acetone sensing properties of porous $\mathrm{WO}_{3}$ nanofibers, Vacuum, 2016, 124, 32-39.

94 A. Ponzoni, et al., Metal Oxide Gas Sensors, a Survey of Selectivity Issues Addressed at the SENSOR Lab, Brescia (Italy), Sensors, 2017, 17, 714.

95 J. E. Cometto-Muñiz, Chemical Sensing in Humans and Machines, in Handbook of Machine Olfaction: Electronic Nose Technology, Wiley-VCH, 2003, pp. 33-53.

96 A. Lee, Temperature modulation in semiconductor gas sensing, Sens. Actuators, B, 1999, 60, 35-42.

97 V. Galstyan, E. Comini, C. Baratto, G. Faglia and G. Sberveglieri, Nanostructured $\mathrm{ZnO}$ chemical gas sensors, Ceram. Int., 2015, 41, 14239-14244.

98 E. Martinelli, D. Polese, A. Catini, A. D'Amico and C. Di Natale, Self-adapted temperature modulation in metaloxide semiconductor gas sensors, Sens. Actuators, B, 2012, 161, 534-541.

99 A. Fort, et al., Selectivity enhancement of $\mathrm{SnO}_{2}$ sensors by means of operating temperature modulation, Thin Solid Films, 2002, 418, 2-8.

100 C. Peng, et al., Synthesis of three-dimensional flower-like hierarchical $\mathrm{ZnO}$ nanostructure and its enhanced acetone gas sensing properties, J. Alloys Compd., 2016, 654, 371-378.

101 S. Wei, J. Zhao and W. Du, Synthesis, characterization and acetone-sensing properties of bristlegrass-like $\mathrm{ZnO}$ nanostructure, Ceram. Int., 2015, 41, 769-776.

102 S. L. Zhang, J. O. Lim, J. S. Huh, J. S. Noh and W. Lee, Twostep fabrication of $\mathrm{ZnO}$ nanosheets for high-performance VOCs gas sensor, Curr. Appl. Phys., 2013, 13, S156-S161.

103 Q. Jia, H. Ji, Y. Zhang, Y. Chen, X. Sun and Z. Jin, Rapid and selective detection of acetone using hierarchical $\mathrm{ZnO}$ gas sensor for hazardous odor markers application, J. Hazard. Mater., 2014, 276, 262-270.

104 K. K. Khun, A. Mahajan and R. K. Bedi, $\mathrm{SnO}_{2}$ thick films for room temperature gas sensing applications, J. Appl. Phys., 2009, 106, 124509.

105 J. Huang, X. Xu, C. Gu, W. Wang, B. Geng, Y. Sun and J. Liu, Effective VOCs gas sensor based on porous $\mathrm{SnO}_{2}$ microcubes prepared via spontaneous phase segregation, Sens. Actuators, B, 2012, 173, 599-606. 
106 C. Gu, X. Xu, J. Huang, W. Wang, Y. Sun and J. Liu, Porous flower-like $\mathrm{SnO}_{2}$ nanostructures as sensitive gas sensors for volatile organic compounds detection, Sens. Actuators, B, 2012, 174, 31-38.

107 T. M. Perfecto, C. A. Zito and D. P. Volanti, Design of nanostructured $\mathrm{WO}_{3} \cdot 0.33 \mathrm{H} 2 \mathrm{O}$ via combination of ultrasonic spray nozzle and microwave-assisted hydrothermal methods for enhancing isopropanol gas sensing at room temperature, CrystEngComm, 2017, 19, 2733-2738.

108 S. S. Shendage, V. L. Patil, S. A. Vanalakar, S. P. Patil, N. S. Harale, J. L. Bhosale, J. K. Kim and P. S. Patil, Sensitive and selective $\mathrm{NO}_{2}$ gas sensor based on $\mathrm{WO}_{3}$ nanoplates, Sens. Actuators, B, 2017, 240, 426-433.

109 N. V. Hieu, V. V. Quang, N. D. Hoa and D. Kim, Preparing large-scale $\mathrm{WO}_{3}$ nanowire-like structure for high sensitivity $\mathrm{NH}_{3}$ gas sensor through a simple route, Curr. Appl. Phys., 2011, 11, 657-661.

110 A. Vomiero, S. Bianchi, E. Comini, G. Faglia, M. Ferroni and G. Sberveglieri, Controlled Growth and Sensing Properties of $\mathrm{In}_{2} \mathrm{O}_{3}$ Nanowires, Cryst. Growth Des., 2003, 7, 2500-2504.

111 J. Gao, H. Wu, J. Zhou, L. Yao, G. Zhang, S. Xu, Y. Xie, L. Li and K. Shi, Mesoporous $\operatorname{In}_{2} \mathrm{O}_{3}$ nanocrystals: synthesis, characterization and $\mathrm{NO}_{\mathrm{x}}$ gas sensor at room temperature, New J. Chem., 2016, 40, 1306-1311.

112 D. Han, L. Zhai, F. Gu and Z. Wang, Highly sensitive $\mathrm{NO}_{2}$ gas sensor of ppb-level detection based on $\operatorname{In}_{2} \mathrm{O}_{3}$ nanobricks at low temperature, Sens. Actuators, B, 2018, 262, 655-663.

113 T. Zhou, T. Zhang, J. Deng, R. Zhang, Z. Lou and L. Wang, Ptype $\mathrm{Co}_{3} \mathrm{O}_{4}$ nanomaterials-based gas sensor: preparation and acetone sensing performance, Sens. Actuators, B, 2017, 242, 369-377.

114 Y. Lin, H. Ji, Z. Shen, Q. Jia and D. Wang, Enhanced acetone sensing properties of $\mathrm{Co}_{3} \mathrm{O}_{4}$ nanosheets with highly exposed (111) planes, J. Mater. Sci.: Mater. Electron., 2015, 27, 2086-2095.

115 W. Yuan and G. Shi, Graphene-based gas sensors, J. Mater. Chem. A, 2013, 1, 10078.

116 K. S. Novoselov, V. I. Falko, L. Colombo, P. R. Gellert, M. G. Schwab and K. Kim, A roadmap for graphene, Nature, 2012, 490, 192-200.

117 B. Kumar, et al., The Role of External Defects in Chemical Sensing of Graphene Field-Effect Transistors, Nano Lett., 2013, 13, 1962-1968.

118 I. S. Kang, H. M. So, G. S. Bang, J. H. Kwak, J. O. Lee and C. Won Ahn, Recovery improvement of graphene-based gas sensors functionalized with nanoscale heterojunctions, Appl. Phys. Lett., 2012, 101, 123504.

119 K. M. Tripathi, T. Kim, D. Losic and T. T. Tung, Recent advances in engineered graphene and composites for detection of volatile organic compounds (VOCs) and noninvasive diseases diagnosis, Carbon, 2016, 110, 97-129.

120 T. T. Tung, M. J. Nine, M. Krebsz, T. Pasinszki, C. J. Coghlan, D. N. H. Tran and D. Losic, Recent Advances in Sensing Applications of Graphene
Assemblies and Their Composites, Adv. Funct. Mater., 2017, 27, 1702891.

121 E. Pargoletti and G. Cappelletti, Breakthroughs in the Design of Novel Carbon-Based Metal Oxides Nanocomposites for VOCs Gas Sensing, Nanomaterials, 2020, 10, 1485.

122 S. S. Varghese, S. Lonkar, K. K. Singh, S. Swaminathan and A. Abdala, Recent advances in graphene-based gas sensors, Sens. Actuators, B, 2015, 218, 160-183.

123 T. Wang, D. Huang, Z. Yang, S. Xu, G. He, X. Li, N. Hu, G. Yin, D. He and L. Zhang, A Review on Graphene-Based Gas/Vapor Sensors with Unique Properties and Potential Applications, Nano-Micro Lett., 2016, 8, 95-119.

124 A. V. Singhal, H. Charaya and I. Lahiri, Noble Metal Decorated Graphene-Based Gas Sensors and Their Fabrication: A Review, Crit. Rev. Solid State Mater. Sci., 2017, 499-526.

125 K. Toda, R. Furue and S. Hayami, Recent progress in applications of graphene oxide for gas sensing: a review, Anal. Chim. Acta, 2015, 878, 43-53.

126 F. L. Meng, Z. Guo and X. J. Huang, Graphene-based hybrids for chemiresistive gas sensors, Trends Anal. Chem., 2015, 68, 37-47.

127 N. Joshi, T. Hayasaka, Y. Liu, H. Liu, O. N. Oliveira and L. Lin, A review on chemiresistive room temperature gas sensors based on metal oxide nanostructures, graphene and 2D transition metal dichalcogenides, Microchim. Acta, 2018, 185, 213.

128 B. Cho, et al., Bifunctional Sensing Characteristics of Chemical Vapor Deposition Synthesized Atomic-Layered $\mathrm{MoS}_{2}$, ACS Appl. Mater. Interfaces, 2015, 7, 2952-2959.

129 F. K. Perkins, A. L. Friedman, E. Cobas, P. M. Campbell, G. G. Jernigan and B. T. Jonker Chemical, Vapor Sensing with Monolayer $\mathrm{MoS}_{2}$, Nano Lett., 2013, 13, 668-673.

130 B. Cho, et al., Charge-transfer-based Gas Sensing Using Atomic-layer $\mathrm{MoS}_{2}$, Sci. Rep., 2015, 5, 8052.

$131 \mathrm{H}$. Li, et al., Fabrication of Single- and Multilayer $\mathrm{MoS}_{2}$ Film-Based Field-Effect Transistors for Sensing NO at Room Temperature, Small, 2011, 8, 63-67.

$132 \mathrm{~T}$. $\mathrm{Xu}$, The ultra-high $\mathrm{NO}_{2}$ response of ultra-thin $\mathrm{WS}_{2}$ nanosheets synthesized by hydrothermal and calcination processes, Sens. Actuators, B, 2018, 259, 789-796.

133 X. Li, X. Li, Z. Li, J. Wang and J. Zhang, $\mathrm{WS}_{2}$ nanoflakes based selective ammonia sensors at room temperature, Sens. Actuators, B, 2017, 240, 273-277.

134 M. O'Brien, K. Lee, R. Morrish, N. C. Berner, N. McEvoy, C. A. Wolden and G. S. Duesberg, Plasma assisted synthesis of $\mathrm{WS}_{2}$ for gas sensing applications, Chem. Phys. Lett., 2014, 615, 6-10.

135 Z. Qin, K. Xu, H. Yue, H. Wang, J. Zhang, C. Ouyang, C. Xie and D. Zeng, Enhanced room-temperature $\mathrm{NH}_{3}$ gas sensing by $2 \mathrm{D} \mathrm{SnS}_{2}$ with sulfur vacancies synthesized by chemical exfoliation, Sens. Actuators, B, 2018, 262, 771-779.

136 S. K. Pandey, R. Das and P. Mahadevan, Layer-Dependent Electronic Structure Changes in Transition Metal Dichalcogenides: The Microscopic Origin, ACS Omega, 2020, 5, 15169-15176. 
$137 \mathrm{~J} . \mathrm{Xu}, \mathrm{J}$. Zhang, W. Zhang and C. S. Lee, Interlayer Nanoarchitectonics of Two-Dimensional Transition-Metal Dichalcogenides Nanosheets for Energy Storage and Conversion Applications, Adv. Energy Mater., 2017, 7, 1700571.

138 E. Lee, Y. S. Yoon and D. J. Kim, Two-dimensional Transition Metal Dichalcogenides and Metal Oxide Hybrids for Gas sensing, ACS Sens., 2018, 3, 2045-2060.

139 S. Yang, C. Jiang and S. H. Wei, Gas sensing in 2D materials, Appl. Phys. Rev., 2017, 4, 021304.

$140 \mathrm{~S}$. Das and V. Jayaraman, $\mathrm{SnO}_{2}$ : a comprehensive review on structures and gas sensors, Prog. Mater. Sci., 2014, 66, 112255.

$141 \mathrm{H}$. W. Kim, et al., Microwave-Assisted Synthesis of Graphene- $\mathrm{SnO}_{2}$ Nanocomposites and Their Applications in Gas Sensors, ACS Appl. Mater. Interfaces, 2017, 9, 31667-31682.

142 Z. Zhang, R. Zou, G. Song, L. Yu, Z. Chen and J. Hu, Highly aligned $\mathrm{SnO}_{2}$ nanorods on graphene sheets for gas sensors, J. Mater. Chem., 2011, 21, 17360.

143 R. Kalidoss, V. J. Surya and Y. Sivalingam, Recent Progress in Graphene Derivatives/Metal Oxides Binary Nanocomposites Based Chemi-resistive Sensors for Disease Diagnosis by Breath Analysis, Curr. Anal. Chem., DOI: $10.2174 / 1573411017999201125203955$.

144 X. Q. Qiao, Z. W. Zhang, D. F. Hou, D. S. Li, Y. Liu, Y. Q. Lan, J. Zhang, P. Feng and X. Bu, Tunable $\mathrm{MoS}_{2} / \mathrm{SnO}_{2} \mathrm{P}-\mathrm{N}$ Heterojunctions for an Efficient Trimethylamine Gas Sensor and 4-Nitrophenol Reduction Catalyst, ACS Sustainable Chem. Eng., 2018, 6, 12375-12384.

$145 \mathrm{Y}$. Han, et al., Construction of $\mathrm{MoS}_{2} / \mathrm{SnO}_{2}$ heterostructures for sensitive $\mathrm{NO}_{2}$ detection at room temperature, Appl. Surf. Sci., 2019, 493, 613-619.

$146 \mathrm{Y}$. Chen, et al., Humidity sensing properties of the hydrothermally synthesized $\mathrm{WS}_{2}$-modified $\mathrm{SnO}_{2}$ hybrid nanocomposite, Appl. Surf. Sci., 2018, 447, 325-330.

147 R. Li, K. Jiang, S. Chen, Z. Lou, T. Huang, D. Chen and G. Shen, $\mathrm{SnO}_{2} / \mathrm{SnS}_{2}$ nanotubes for flexible roomtemperature $\mathrm{NH}_{3}$ gas sensors, RSC Adv., 2017, 7, 5250352509.

148 R. Ghosh, A. K. Nayak, S. Santra, D. Pradhan and P. K. Guha, Enhanced ammonia sensing at room temperature with reduced graphene oxide/tin oxide hybrid films, RSC Adv., 2015, 5, 50165-50173.

$149 \mathrm{~J} . \mathrm{Hu}$, et al., Formaldehyde Sensing Performance of Reduced Graphene Oxide-Wrapped Hollow $\mathrm{SnO}_{2}$ Nanospheres Composites, Sens. Actuators, B, 2019, 307, 127584.

150 F. Wang, H. Liu, K. Hu, Y. Li, W. Zeng and L. Zeng, Hierarchical composites of $\mathrm{MoS}_{2}$ nanoflower anchored on $\mathrm{SnO}_{2}$ nanofiber for methane sensing, Ceram. Int., 2019, 45, 22981-22986.

151 S. Singh, S. Kumar and S. Sharma, Room temperature high performance ammonia sensor using $\mathrm{MoS}_{2} / \mathrm{SnO}_{2}$ nanocomposite, Mater. Today: Proc., 2020, 28, 52-55.
$152 \mathrm{Y}$. Chen, et al., Humidity sensing properties of the hydrothermally synthesized $\mathrm{WS}_{2}$-modified $\mathrm{SnO}_{2}$ hybrid nanocomposite, Appl. Surf. Sci., 2018, 447, 325-330.

153 J. Liu, S. Li, B. Zhang, Y. Xiao, Y. Gao, Q. Yang, Y. Wang and G. Lu, Ultrasensitive and low detection limit of nitrogen dioxide gas sensor based on flower-like $\mathrm{ZnO}$ hierarchical nanostructure modified by reduced graphene oxide, Sens. Actuators, B, 2017, 249, 715-724.

154 X. Chang, X. Qiao, K. Li, P. Wang, Y. Xiong, X. Li, F. Xia and Q. Xue, UV assisted ppb-level acetone detection based on hollow $\mathrm{ZnO} / \mathrm{MoS}_{2}$ nanosheets core/shell heterostructures at low temperature, Sens. Actuators, B, 2020, 317, 128208.

155 D. Zhang, C. Jiang and Y. Sun, Room-temperature highperformance ammonia gas sensor based on layer-by-layer self-assembled molybdenum disulfide/zinc oxide nanocomposite film, J. Alloys Compd., 2017, 698, 476-483.

156 S. Zhao, G. Wang, J. Liao, S. Lv, Z. Zhu and Z. Li, Vertically aligned $\mathrm{MoS}_{2} / \mathrm{ZnO}$ nanowires nanostructures with highly enhanced $\mathrm{NO}_{2}$ sensing activities, Appl. Surf. Sci., 2018, 456, 808-816.

157 H. Yan, P. Song, S. Zhang, Z. Yang and Q. Wang, Facile synthesis, characterization and gas sensing performance of ZnO nanoparticles-coated $\mathrm{MoS}_{2}$ nanosheets, J. Alloys Compd., 2016, 662, 118-125.

158 S. Choi, C. Choi, S. J. Kim, H. J. Cho, M. Hakim, S. Jeon and I. Kim, Highly Efficient Electronic Sensitization of Nonoxidized Graphene Flakes on Controlled Pore-loaded $\mathrm{WO}_{3}$ Nanofibers for Selective Detection of $\mathrm{H}_{2} \mathrm{~S}$ Molecules, Sci. Rep., 2015, 5, 8067.

159 S. Srivastava, K. Jain, V. N. Singh, S. Singh, N. Vijayan, N. Dilawar, G. Gupta and T. D. Senguttuvan, Faster response of $\mathrm{NO}_{2}$ sensing in graphene- $\mathrm{WO}_{3}$ nanocomposites, Nanotechnology, 2012, 23, 205501.

160 S. Singh, N. Dogra and S. Sharma, A sensitive $\mathrm{H}_{2} \mathrm{~S}$ sensor using $\mathrm{MoS}_{2} / \mathrm{WO}_{3}$ composite, Mater. Today: Proc., 2020, 28, 8-10.

161 D. Acharyya and P. Bhattacharyya, Highly Efficient RoomTemperature Gas Sensor Based on $\mathrm{TiO}_{2}$ NanotubeReduced Graphene-Oxide Hybrid Device, IEEE Electron Device Lett., 2016, 37, 656-659.

162 P. X. Zhao, Y. Tang, J. Mao, Y. X. Chen, H. Song, J. W. Wang, Y. Song, Y. Q. Liang and X. M. Zhang, One-Dimensional $\mathrm{MoS}_{2}$-Decorated $\mathrm{TiO}_{2}$ nanotube gas sensors for efficient alcohol sensing, J. Alloys Compd., 2016, 674, 252-258.

163 Z. Qin, C. Ouyang, J. Zhang, L. Wan, S. Wang, C. Xie and D. Zeng, 2D $\mathrm{WS}_{2}$ nanosheets with $\mathrm{TiO}_{2}$ quantum dots decoration for high-performance ammonia gas sensing at room temperature, Sens. Actuators, B, 2017, 253, 1034-1042.

164 N. Van Hoang, et al., Enhanced $\mathrm{H}_{2} \mathrm{~S}$ gas-sensing performance of $\alpha-\mathrm{Fe}_{2} \mathrm{O}_{3}$ nanofibers by optimizing process conditions and loading with reduced graphene oxide, $J$. Alloys Compd., 2020, 826, 154169.

165 S. J. Choi, W. H. Ryu, S. J. Kim, H. J. Cho and I. D. Kim, Bifunctional co-sensitization of graphene oxide sheets and Ir nanoparticles on p-type $\mathrm{Co}_{3} \mathrm{O}_{4}$ nanofibers for selective acetone detection, J. Mater. Chem. B, 2014, 2, 7160-7167. 
166 D. Zhang, C. Jiang, P. Li and Y. Sun, Layer-by-Layer Selfassembly of $\mathrm{Co}_{3} \mathrm{O}_{4}$ Nanorod-Decorated $\mathrm{MoS}_{2}$ NanosheetBased Nanocomposite toward High-Performance Ammonia Detection, ACS Appl. Mater. Interfaces, 2017, 9, 6462-6471.

167 L. Zhou, F. Shen, X. Tian, D. Wang, T. Zhang and W. Chen, Stable $\mathrm{Cu}_{2} \mathrm{O}$ nanocrystals grown on functionalized graphene sheets and room temperature $\mathrm{H}_{2} \mathrm{~S}$ gas sensing with ultrahigh sensitivity, Nanoscale, 2013, 5, 1564.

168 F. Perrozzi, S. M. Emamjomeh, V. Paolucci, G. Taglieri, L. Ottaviano and C. Cantalini, Thermal stability of $\mathrm{WS}_{2}$ flakes and gas sensing properties of $\mathrm{WS}_{2} / \mathrm{WO}_{3}$ composite to $\mathrm{H}_{2}, \mathrm{NH}_{3}$ and $\mathrm{NO}_{2}$, Sens. Actuators, $B, 2017,243,812-822$.

169 R. Kalidoss and S. Umapathy, A comparison of online and offline measurement of exhaled breath for diabetes prescreening by graphene-based sensor; from powder processing to clinical monitoring prototype, J. Breath Res., 2019, 13, 036008.

170 R. Kalidoss, S. Umapathy, R. Kothalam and U. Sakthivel, Adsorption kinetics feature extraction from breathprint obtained by graphene based sensors for diabetes diagnosis, J. Breath Res., 2020, 15, 016005.

171 S. Umapathy, N. Nasimsha, M. Kumar, R. Kalidoss, A. Catherin, L. Madhavi and E. G. Rinzan, Design and development of portable prototype for human breath analysis: a comparative study between haemodialysis patients and healthy subjects, Biomed. Phys. Eng. Express, 2019, 5, 025045.

172 B. Shan, et al., Multiplexed Nanomaterial-Based Sensor Array for Detection of COVID-19 in Exhaled Breath, ACS Nano, 2020, 14, 12125-12132.

173 R. D. Vries, J. W. F. Dagelet, U. Frey, R. Lutter, A. M. Zee, P. Sterk and A. Sinha, Assessment of repeatability of eNose (SpiroNose) measurements in healthy and asthmatic subjects, Eur. Respir. J., 2018, 52, OA315.

174 R. D. Vries, P. Brinkman, N. Fens, E. Dijkers, S. Bootsma, et al., C32 Clinical Asthma II: Integration Of Electronic Nose Technology With Spirometry: Validation Of A New Approach For Clinical Breath Analysis, Am. J. Respir. Crit. Care Med., 2015, 191, 1.

175 C. G. Waltman, T. A. T. Marcelissen and J. G. H. van Roermund, Exhaled-breath Testing for Prostate Cancer Based on Volatile Organic Compound Profiling Using an Electronic Nose Device (Aeonose ${ }^{\mathrm{TM}}$ ): A Preliminary Report, Eur. Urol. Focus, 2020, 6, 1220-1225.

176 E. Krauss, J. Haberer, G. Barreto, M. Degen, W. Seeger and A. Guenther, Recognition of breathprints of lung cancer and chronic obstructive pulmonary disease using the Aeonose® electronic nose, J. Breath Res., 2020, 14, 046004.

177 E. Krauss, J. Zoelitz, J. Wagner, G. Barretto, M. Degen, W. Seeger and A. Guenther, The use of electronic nose technology for the detection of Lung Cancer (LC): analysis of exhaled volatile compounds by Aeonose ${ }^{\circledR}$, Eur. Respir. J., 2018, 52, 1758.

178 K. E. Van Keulen, M. E. Jansen, R. W. M. Schrauwen, J. J. Kolkman and P. D. Siersema, Volatile organic compounds in breath can serve as a non-invasive diagnostic biomarker for the detection of advanced adenomas and colorectal cancer, Aliment. Pharmacol. Ther., 2019, 51, 334-346.

179 E. G. M. Steenhuis, I. J. H. Schoenaker, J. W. B. de Groot, H. B. Fiebrich, J. C. de Graaf, R. M. Brohet, J. D. van Dijk, H. L. van Westreenen, P. D. Siersema and W. H. de Vos tot Nederveen Cappel, Feasibility of volatile organic compound in breath analysis in the follow-up of colorectal cancer: a pilot study, Eur. J. Surg. Oncol., 2020, 46, 2068-2073.

180 D. Germanese, S. Colantonio, M. D'Acunto, V. Romagnoli, A. Salvati and M. Brunetto, An E-Nose for the Monitoring of Severe Liver Impairment: A Preliminary Study, Sensors, 2019, 19, 3656.

181 T. Hibbarda, K. Crowleya and A. J. Killardab, Direct measurement of ammonia in simulated human breath using an inkjet-printed polyaniline nanoparticle sensor, Anal. Chim. Acta, 2013, 779, 56-63.

182 R. Kalidoss and S. Umapathy, An overview on the exponential growth of non-invasive diagnosis of diabetes mellitus from exhaled breath by nanostructured metal oxide Chemi-resistive gas sensors and $\mu$-preconcentrator, Biomed. Microdevices, 2019, 3, 2.

183 W. Miekisch, J. K. Schubert, F. E. Gabriele and N. Schomburg, Diagnostic potential of breath analysisfocus on volatile organic compounds, Clin. Chim. Acta, 2004, 347, 25-39.

184 J. E. Fitzgerald, E. T. H. Bui, N. M. Simon and H. Fenniri, Artificial Nose Technology: Status and Prospects in Diagnostics, Trends Biotechnol., 2017, 35, 33-42.

185 B. Henderson, et al., A benchmarking protocol for breath analysis: the peppermint experiment, J. Breath Res., 2020, 14, 046008.

186 J. S. Tsuji, A. D. Maynard, P. C. Howard, J. T. James, C. W. Lam, D. B. Warheit and A. B. Santamaria, Research strategies for safety evaluation of nanomaterials, part IV: risk assessment of nanoparticles, Toxicol. Sci., 2006, 89, 42-45.

187 ETC Group, No Small Matter II: The Case for a Global Moratorium - Size Matters!, 2003.

188 E. Wu, C. Chan and A. T. W. Li, On the evaluation of the safety aspects of nanomaterials in medical devices a regulatory perspective, $A D M E T \& D M P K, 2013,1,76-81$. 